NBER WORKING PAPER SERIES

\title{
BIASES IN STATIC OLIGOPOLY MODELS? \\ EVIDENCE FROM THE CALIFORNIA ELECTRICITY MARKET
}

\author{
Dae-Wook Kim \\ Christopher R. Knittel \\ Working Paper 10895 \\ http://www.nber.org/papers/w10895
}

\author{
NATIONAL BUREAU OF ECONOMIC RESEARCH \\ 1050 Massachusetts Avenue \\ Cambridge, MA 02138 \\ November 2004
}

We thank Severin Borenstein, Jim Bushnell, Erin Mansur, Steve Puller, Victor Stango and Catherine Wolfram for helpful comments. We also thank Severin Borenstein, Jim Bushnell and Frank Wolak for providing us with their marginal cost data. Kim gratefully acknowledges support from the California Energy Commission, while Knittel gratefully acknowledges support from the University of California Energy Institute. The views expressed herein are those of the author(s) and not necessarily those of the National Bureau of Economic Research.

(C) 2004 by Dae-Wook Kim and Christopher R. Knittel. All rights reserved. Short sections of text, not to exceed two paragraphs, may be quoted without explicit permission provided that full credit, including (C) notice, is given to the source. 
Biases in Static Oligopoly Models? Evidence from the California Electricity Market Dae-Wook Kim and Christopher R. Knittel

NBER Working Paper No. 10895

November 2004

JEL No. L1, L5, L9

\begin{abstract}
$\underline{\text { ABSTRACT }}$
Estimating market power is often complicated by the lack of reliable measures of marginal cost. Instead, policy-makers often rely on other summary statistics of the market, thought to be correlated with price cost margins---such as concentration ratios or the HHI. In many industries, these summary statistics may be only weakly correlated with deviations from perfectly competitive pricing. Beginning with Gollop and Roberts (1979), a number of empirical studies have allowed the data to identify industry competition and marginal cost levels by estimating the firms' first order condition within a conjectural variations framework. Despite the prevalence of such "New Empirical Industrial Organization" (NEIO) studies, Corts (1999) illustrates the estimated mark-up levels may be biased, since the estimated conjectural variations model forces the supply relationship to be a ray through the marginal cost intercept, whereas this need not be true in dynamic games. In this paper, we use direct measures of marginal cost for the California electricity market to measure the extent to which estimated mark-ups and marginal costs are biased. Our results suggest that the NEIO technique poorly estimates the level of mark-ups and the sensitivity of marginal cost to cost shifters.

Dae-Wook Kim

University of California at Davis

Department of Economics

One Shields Ave

Davis, CA 95616

daekim@ucdavis.edu

Christopher R. Knittel

University of California at Davis

Department of Economics

One Shields Ave

Davis, CA 95616

and NBER

crknittel@ucdavis.edu
\end{abstract}




\section{Introduction}

Estimating market power is often complicated by the lack of reliable measures of marginal cost. Instead, policy-makers often rely on summary statistics of the market, thought to be correlated with price cost margins - such as concentration ratios or the HHI. In many industries, these summary statistics may be only weakly correlated with deviations from perfectly competitive pricing. Borenstein, Bushnell and Knittel (1999) show that these measures may actually be negatively correlated with market power levels in restructured electricity markets.

Beginning with Gollop and Roberts (1979), "New Empirical Industrial Organization" (NEIO) studies have estimated price-cost margins by estimating the firms' first order condition within a conjectural variations framework. Marginal costs are treated as a function of observable cost shifters and a set of unknown parameters. By observing fluctuations in demand over time (or cross-sectionally), marginal costs are identified through the firms' first order conditions, which relate prices to marginal costs, the "conduct parameter" and the elasticity of demand. The use of these models has been extensive. ${ }^{1}$ Despite the prevalence of such studies, Corts (1999) illustrates the estimated conduct parameter may be biased, since the estimated conduct parameter forces the supply relationship to be a ray through the marginal cost intercept, whereas this need not be true in dynamic games. Because policy can often hinge on these estimates, it is important to understand the extent of this bias, and, if possible, its direction. For example, perceived market power in California's electricity industry prompted a number of policy changes and lawsuits; many antitrust actions are also based on the level of market power in an industry.

In this paper, we take advantage of unique data that allow us to quantify the degree of error inherent in the NEIO estimates. We analyze the NEIO methods using a number of metrics. First, we use direct measures of marginal cost to calculate price-cost margins and compare these to the estimates derived from the NEIO technique. Second, we calculate the hourly estimates of marginal cost and compare them to actual marginal cost levels. Third, we compare the sensitivity of the estimated marginal cost to cost shifters with the sensitivity of actual marginal cost to the same set of cost shifters. To test the robustness of these results,

\footnotetext{
${ }^{1}$ See, for example, Brander and Zhang (1990), Applebaum (1983), Porter (1983), Roberts (1984), Spiller and Favaro (1984), Gelfand and Spiller (1987), Brander and Zhang (1993), Ellison (1994), Berg and Kim (1994) and Graddy (1995), Nebesky, McMullen, Lee (1995), Kadiyali (1996), Kadiyali (1999), Kadiyali, Vilcassim, Chintagunta (1999), Raper, Love and Shumway (2000).
} 
we estimate a number of functional forms of both demand and marginal costs. In addition, we extend Corts' analytical results to show the conditions in which the NEIO estimate is unbiased in a dynamic setting.

Our empirical setting is the restructured California electricity market. Concerns regarding market power levels in restructured electricity markets are especially high, as many industry observers argue prices have far exceeded marginal costs. Fortunately, as a result of the long history of regulation and the relative transparency of the production technology, detailed cost data for electricity markets are currently available. These data have been used to calculate the level of market power, measured as Lerner and elasticity-adjusted Lerner indexes, in the UK and California markets. Wolfram (1999) compares UK wholesale electricity prices with marginal costs. Her results suggest the average elasticity-adjusted Lerner index is small. Borenstein, Bushnell and Wolak (2002) and Joskow and Kahn (2001) estimate hourly marginal cost for the California market and compare these estimates to wholesale prices. They find that in certain time periods prices substantially exceeded marginal cost.

While reliable marginal cost data for the electricity industry are currently available, this is unlikely to continue for a number of reasons. Entrants into these markets - independent power producers - do not face the same data regulations as the traditional investor owned utilities. In addition, there is evidence that existing firms are lobbying policy-makers to make cost data unavailable to the public. The absence of reliable data in the future increases the importance of evaluating methods that infer price-cost margins without cost data while the data are currently available. We estimate market power and marginal costs under the assumption that firm-level data are unavailable; we employ only data that are likely to be available in the future: market level prices, quantities and demand and cost shifters. As such our focus is not on individual firm conduct, but instead on the ability to estimate the efficiency of the market as a whole without detailed cost data. Our results suggest that the NEIO technique does a poor job of estimating market power levels, although this is functional form dependent. Furthermore the NEIO estimates of marginal cost do not measure the sensitivity of marginal cost to cost shifters well.

Absent the "Corts' critique," the interpretation of the conduct parameter has also been controversial. Taking the conjectural variation model literally, the parameter represents a firm's beliefs regarding how its competitors will react if the firm changes its quantity. Unfortunately, the theoretical literature has shown that the behavioral parameter represents a consistent equilibrium only under very specific information assumptions. (Lindh [1992]) If 
one eschews the CV model as a model of conduct and instead views the "conduct parameter" as simply a summary of the market's competitiveness, the estimated conduct parameter measures the elasticity-adjusted Lerner index - this is referred to as the "as-if" conduct parameter. The focus of this paper is not whether the estimated conduct parameter accurately reflects the firms' beliefs, but whether the estimated conduct parameter accurately reflects the elasticity-adjusted Lerner index of the industry.

Our work adds to a small body of recent work examining the accuracy of NEIO techniques. Genesove and Mullin (1998) use data from the sugar industry during the late 19th and early 20th centuries; the transparency of sugar's cost technology and its heavy reliance on the price of sugar cane allow them to accurately estimate marginal costs. Their results are listed in Table 1. They find that the direct measure of the elasticity-adjusted Lerner index falls outside the 95 percent confidence interval of the NEIO estimate, and that the NEIO estimate understates margins; however, in economic terms, the difference is not large. The NEIO technique estimates the elasticity-adjusted Lerner index to be .038, when its actual value is .107. In a recent paper, Clay and Troesken (2003) replicate Genesove and Mullin for the whiskey industry during the late nineteenth century. They also find that the actual elasticity-adjusted Lerner index falls outside of the 95 percent confidence interval of the NEIO estimate. Unlike Genesove and Mullin, they find that the NEIO technique over-states mark-ups for each of the estimated function forms. Another related paper is Wolfram (1999) which studies the deregulated UK electricity market. Wolfram finds that the NEIO technique

provides a noisy estimate of market power; neither perfect competition nor equality to the actual level of mark-ups can be rejected.

The paper proceeds as follows: Section 2 discusses the empirical framework. The empirical setting and data are discussed in Section 3. Section 4 discusses the results, while section 5 investigates the robustness of the results. Section 6 concludes the paper and offers directions for future research.

\section{Empirical Framework}

We begin by characterizing market $i$ 's equilibrium price within a conjectural variations model:

$$
P\left(Q_{i}, X_{i} ; \beta_{1}\right)+\theta Q_{i} P^{\prime}\left(Q_{i}, X_{i} ; \beta_{1}\right)=C^{\prime}\left(Q_{i}, Z_{i} ; \beta_{2}\right)
$$


where $P\left(Q_{i}, X_{i} ; \beta_{1}\right)$ is the market inverse demand function, $C^{\prime}\left(Q_{i}, Z_{i} ; \beta_{2}\right)$ is the market marginal cost function, $Q_{i}$ is the market level quantity, $X_{i}$ is a vector of variables that affect demand, $Z_{i}$ is a vector of variables that affect costs and $\beta_{1}$ and $\beta_{2}$ are vectors of unknown parameters associated with demand and costs, respectively.

The parameter $\theta$ is an estimate of the elasticity-adjusted Lerner index. To see this, we can solve for $\theta$ :

$$
\theta=\frac{P_{i}-M C_{i}}{P_{i}} \eta
$$

Identification of $\theta$ relies on variation in demand across time or across markets. The model nests joint profit maximization $(\theta=1)$, perfect competition $(\theta=0)$ and the Cournot equilibrium $(\theta=1 / N)$.

The typical empirical implementation of the NEIO technique uses data on industry level prices, quantities and demand and cost determinants. Depending on the functional form, equation (1) can be isolated for $P$ as a function of some measure of the responsiveness of demand and marginal cost shifters. For example, if demand is linear, then equation (1) becomes:

$$
P_{i}=\frac{M C_{i}}{1+\theta}+\frac{\theta}{1+\theta} \frac{a_{i}}{b_{i}}
$$

where $a_{i}$ is the demand intercept and $b_{i}$ is the slope. Demand can either be estimated jointly with the supply equation or estimated separately, yielding observations on $\frac{a}{b}$. Marginal costs are often expressed as a function of cost determinants and an error term is assumed to account for unobservables, yielding:

$$
P_{i}=Z_{i} \frac{\gamma}{1+\theta}+\frac{\theta}{1+\theta} \frac{a_{i}}{b_{i}}+\varepsilon_{i}
$$

\subsection{Corts' Critique}

The relevance of equation (1) has been questioned on two fronts. For one, because the pricing rule is the result of a conjectural variations model, it need not represent a Nash equilibrium. A number of authors have defended the method on this front, however. The basis of the defense is that the conjectural variations model is only proxying for a dynamic model, and the Folk theorem tells us that a range of conducts are Nash equilibria in a dynamic game. Therefore, the parameter estimate from the NEIO technique should be viewed as only a 
measure of the elasticity-adjusted Lerner index and can be thought of as the static-equivalent measure of an industry's competitiveness - an "as-if" estimate of market power.

More damning to the supporters of NEIO technique is Corts (1999). Corts illustrates that the conduct parameter estimated from equation (1) can be biased even if the econometrician views $\theta$ as an "as-if" estimate of behavior. The intuition is simple. The pricing rule in equation (1) is the solution to the firms' static first order conditions. If firms are competing in a dynamic setting, then the firms' first order conditions may also depend on the incentive compatibility constraints associated with collusion - that no one firm has an incentive to deviate. If the incentive compatibility constraints are a function of demand shocks, then the estimated $\theta$ may be biased.

More formally, consider a static model, the as-if conduct parameter is defined as the elasticity-adjusted Lerner index:

$$
\begin{aligned}
\theta & =\frac{P-C^{\prime}}{P} \eta \\
& =-\frac{P-C^{\prime}}{Q} / \frac{\partial P\left(Q, X ; \beta_{1}\right)}{\partial Q} \\
& =-\frac{1}{\frac{\partial P\left(Q, X ; \beta_{1}\right)}{\partial Q}} \frac{\left(P-C^{\prime}\right)}{X} / \frac{Q}{X}
\end{aligned}
$$

Corts illustrates that the NEIO technique identifies $\theta$ by "observing" variation in $P, Q$ and $X$. In particular, Corts illustrates that the fundamental variation is $\frac{\partial\left(P-C^{\prime}\right)}{\partial X} / \frac{\partial Q}{\partial X}$. Specifically, Corts shows that:

$$
\hat{\theta}=-\frac{1}{\frac{\partial P\left(Q, X ; \beta_{1}\right)}{\partial Q}} \frac{\partial\left(P-C_{i}^{\prime}\right)}{\partial X} / \frac{\partial Q}{\partial X}
$$

where $\hat{\theta}$, is the NEIO estimate of $\theta$ and $\frac{\partial P\left(Q, X ; \beta_{1}\right)}{\partial Q}$ is treated as "data" obtained from a first-stage regression. The conduct parameter is identified since the econometrician observes how prices change $\left(\frac{\partial P\left(Q, X ; \beta_{1}\right)}{\partial X}\right)$ and quantities change $\left(\frac{\partial Q}{\partial X}\right)$ when $X$ changes; the additional parameters $\left(\frac{\partial C^{\prime}}{\partial X}\right.$ and $\left.\hat{\theta}\right)$ are identified through the equality restriction.

The econometrician observes how the price cost margin varies with changes in $X$; whereas she is interested in the level of the price cost margin. It is possible, for example in a dynamic game, that two industries exhibit the same variation in $P-C^{\prime}$ from a change in $X$ despite having vastly different levels of $P-C^{\prime}$. Comparing equations (5) and (6), for $\hat{\theta}$ to be unbiased, we require: 


$$
\frac{\partial\left(P-C^{\prime}\right)}{\partial X} / \frac{\partial Q}{\partial X}=\frac{\left(P-C^{\prime}\right)}{X} / \frac{Q}{X}
$$

Nevertheless, we have the following proposition:

Proposition 1: In a static setting, the NEIO estimator, $\hat{\theta}$, is an unbiased estimator of the as-if parameter, $\tilde{\theta}$.(Corts [1999])

Proof. Solving the as-if parameter for $\left(P-C_{i}^{\prime}\right)$ and differentiating with respect to $X$ (treating $\frac{\partial P\left(Q, X_{i} ; \beta_{1}\right)}{\partial q}$ as fixed), the as-if parameter is given as:

$$
\begin{gathered}
\frac{\partial\left(P-C^{\prime}\right)}{\partial X}=-\tilde{\theta} \frac{\partial P\left(Q, X ; \beta_{1}\right)}{\partial Q} \frac{\partial Q}{\partial X} \\
\Rightarrow \tilde{\theta}=\quad-\frac{1}{\frac{\partial P\left(Q, X ; \beta_{1}\right)}{\partial Q}} \frac{\partial\left(P-C^{\prime}\right)}{\partial X} / \frac{\partial Q}{\partial X}
\end{gathered}
$$

Comparing this to equation (6), we see that this is the NEIO estimator. QED.

If firms are competing in a dynamic game, this condition may not hold. The static first order condition will differ from the dynamic first order condition because in a dynamic game the firms' first order conditions have an additional term reflecting the incentive compatibility constraint associated with collusion; furthermore, this incentive compatibility constraint may be a function of demand shocks. Denoting this term as $I(\cdot)$, the first order condition becomes:

$$
P+\theta \frac{\partial P\left(Q, X ; \beta_{1}\right)}{\partial Q} Q-C^{\prime}\left(Q, Z ; \beta_{2}\right)-I(\cdot)=0
$$

Proposition 2: In a dynamic setting, the NEIO estimator, $\hat{\theta}$, is an unbiased estimator of $\tilde{\theta}$ provided if $\frac{\partial I(\cdot)}{\partial X} / \frac{\partial q}{\partial X}=\frac{I(\cdot)}{X} / \frac{q}{X}=0$.

Proof. The NEIO estimator continues to be $-\frac{1}{\frac{\partial P\left(Q, X ; \beta_{1}\right)}{\partial q}} \frac{\partial\left(P-C^{\prime}\right)}{\partial X} / \frac{\partial Q}{\partial X}$; however from the dynamic first order condition, we have:

$$
\hat{\theta}=-\frac{1}{\frac{\partial P\left(Q, X ; \beta_{1}\right)}{\partial Q}} \frac{\partial\left(P-C^{\prime}\right)}{\partial X} / \frac{\partial Q}{\partial X}=\theta+\frac{1}{\frac{\partial P\left(Q, X ; \beta_{1}\right)}{\partial Q}} \frac{\partial I(\cdot)}{\partial X} / \frac{\partial Q}{\partial X}
$$

In contrast, the as-if estimator is actually an estimate of:

$$
\tilde{\theta}=\theta+\frac{1}{\frac{\partial P\left(Q, X ; \beta_{1}\right)}{\partial Q}} \frac{I(\cdot)}{X} / \frac{Q}{X}
$$

These are equal if: 


$$
\frac{\partial I(\cdot)}{\partial X} / \frac{\partial Q}{\partial X}=\frac{I(\cdot)}{X} / \frac{Q}{X}
$$

QED.

This proposition implies that the NEIO estimator will be unbiased if the marginal change in the incentive compatibility constraint equals the average. This is similar to the condition for the static case where the marginal change in the price cost margin must equal the average in the price cost margin. Corts discusses one such case - if the discount factor is small enough such that firms are colluding at the monopoly price. To see this is true, if firms are colluding at the monopoly price then we have:

$$
P+\frac{\partial P\left(Q, X ; \beta_{1}\right)}{\partial Q} Q-C^{\prime}\left(Q, Z ; \beta_{2}\right)=0
$$

If we equate this to the dynamic first order condition in the conjectural variations framework, we have

$$
\begin{aligned}
\theta \frac{\partial P\left(Q, X ; \beta_{1}\right)}{\partial Q} Q-I(\cdot) & =\frac{\partial P\left(Q, X ; \beta_{1}\right)}{\partial Q} Q \\
& \Rightarrow I(\cdot)=\theta \frac{\partial P\left(Q, X ; \beta_{1}\right)}{\partial Q} Q-\frac{\partial P\left(Q, X ; \beta_{1}\right)}{\partial Q} Q
\end{aligned}
$$

From this we can see that (again treating $\frac{\partial P\left(Q, X ; \beta_{1}\right)}{\partial Q}$ as fixed), $\frac{\partial I(\cdot)}{\partial X} / \frac{\partial Q}{\partial X}=\frac{I(\cdot)}{X} / \frac{Q}{X}$.

In contrast, if the incentive compatibility constraint is binding then an increase in $X$ increases the incentive to cheat. For example, consider the Rotemberg and Saloner (1986) model of collusion. Each period the demand intercept is drawn from a distribution that is iid across time. Firms observe the demand shock $(X)$ and set prices so as to meet the incentive compatibility constraint. Consider the case where the incentive compatibility constraint binds for the expected level of $X$. If $X$ is larger than $E[X]$, prices will fall since the benefits from cheating have increased, while the present value of punishment from cheating is not affected. Therefore, the NEIO estimate of $\theta$ will be biased downward since the data suggest that $\frac{\partial\left(P-C^{\prime}\right)}{\partial X} / \frac{\partial Q}{\partial X}$ is negative during some periods.

In contrast, if firms are sufficiently patient such that the incentive compatibility constraint never binds, then the NEIO proposition 2 shows that the NEIO estimate will be unbiased. 


\section{Empirical Setting}

\subsection{Institutional Detail}

The restructured wholesale California electricity market began operation in April of 1998. Prior to 2001, wholesale electricity was primarily traded in two separate markets. The now defunct Power Exchange (PX) organized a day-ahead market and was one of many "Scheduling Coordinators" (SCs). The PX had an advantage over other SCs because California's three IOUs; Pacific Gas and Electric, Southern California Edison and San Diego Gas and Electric were initially required to trade through the PX. Electricity that was not traded through a scheduling coordinator, was traded through the Independent System Operator (ISO), which operated an "imbalance market" designed to instantaneously equate supply and demand.

For system reliability reasons, it was envisioned that the vast majority of energy would be traded in the PX market; only unforeseen shocks to supply or demand would be traded in the ISO. ${ }^{2}$ The transparency of trading the bulk of electricity in the day prior to delivery allowed market organizers sufficient time to plan the use of the state's transmission grid.

The PX worked as follows: At 7am each morning, suppliers and demanders submitted hourly schedules of bids for the following day (beginning at 12am), constituting individual supply and demand bids for each hour of the day. The PX aggregated these bids into one hourly supply bid and one hourly demand bid. The intersection of these bids determined the "unconstrained" PX price for each hour of the day. The PX then submitted its "preferred" prices and quantities to the ISO. Provided the preferred schedule did not result in any transmission congestion, the unconstrained PX price became the market clearing price. If the preferred schedule (along with the schedules of other scheduling coordinators) resulted in congestion, another round of bidding was used to reduce the demand (or increase the supply) in certain areas of California. In our analysis, we follow the existing literature and use the unconstrained PX price as the market clearing price. ${ }^{3}$

\subsection{Measuring Marginal Cost}

The California electricity industry is an ideal setting for analyzing NEIO techniques for a number of reasons. The bulk of electricity that is generated in California is produced using

\footnotetext{
${ }^{2}$ During the PX's operation, over $80 \%$ of energy was traded in the PX.

${ }^{3}$ See, for example, Borenstein, Bushnell and Wolak (2002).
} 
fossil fuel generation plants; furthermore fossil-fuel plants are predominantly the marginal plant operating. Accurate estimates of the short-run marginal cost of fossil-fuel electricity generating plants can be calculated since their thermal efficiencies at different output levels are well known and spot market prices of natural gas are available. For each plant, a heat rate is available which measures the efficiency in the which the plant converts fuel to electricity. Given a fuel price the component of marginal cost attributed to fuel can be computed. The remaining components of marginal cost are operation and maintenance costs. We make use of the marginal cost data from Borenstein, Bushnell and Wolak (2002); we refer the reader to their work for details of the process.

We make one adjustment to their measure of marginal cost. In 45 percent of the hours price is below their measure of marginal cost. This likely reflects firms' inter-temporal constraints to shutting down power plants, since rational agents would not price below true marginal cost. ${ }^{4}$ To control for this, we define marginal cost as:

$$
\min \left(P_{t}, M C_{t, B B W}\right)
$$

This will tend to overestimate of marginal cost during low demand periods, when these intertemporal constraints are binding, since during those hours we know only that marginal cost is, at most, equal to the price. ${ }^{5}$

Figure 1 is a scatter-plot of system-wide marginal cost on quantity along with a Lowess non-parametric regression estimate of the relationship. It is apparent that the market faces a capacity constraint - although the regression line does not become vertical only steeper as quantity becomes large. To capture this feature of marginal cost, below we initially assume that marginal costs are quadratic in quantity; we also estimate an endogenous spline model.

\subsection{Estimation of Demand}

The demand for electricity is extremely inelastic. Compounding the inelastic nature of demand is the fact that only a small percentage of demand actually observes wholesale prices. During the time periods analyzed in this paper, retail consumers faced a fixed price, that is, at least in the short run, independent of wholesale prices. Therefore, retail consumers

\footnotetext{
${ }^{4}$ Plants face non-trivial start up costs, implying a firm may be willing to run a plant when the price is below the plants static marginal costs if price is expected to rise in the coming hours. The results are robust to excluding these observations.

${ }^{5}$ We analyze alternative assumptions below.
} 
show no demand response to changes in the wholesale prices. These features of the market suggest that short run demand is best viewed as being perfectly inelastic. However, for issues of market power, the relevant elasticity measure is the elasticity faced by "strategic" firms in the market, since some firms may not possess unilateral market power - supplying electricity until their marginal cost equals price. Following Borenstein, Bushnell, and Wolak (2002) and Puller (2002), we define a set of firms as "non-strategic" and a set of firms that are "strategic." Firms that do not act strategically act as price takers and submit bids into the market equal to their marginal cost. Strategic firms, in contrast, incorporate their ability to influence price into their bid functions. Following Borenstein, Bushnell and Wolak, we assume that in-state fossil fuel generators are strategic and estimate the level of market power possessed by these generators.

Table 2 reports the in-state firms' generation facilities in July of 1999 by fuel type. Viewing fossil fuel generation as strategic and other fuel types as non-strategic, the California electricity market is roughly characterized as 5 equally sized strategic firms. In contrast to fossil fuel generation, hydroelectric and nuclear generation facilities are owned by the two largest retailers in California-PG\&E and Southern California Edison. Because during most hours these firms are net buyers of electricity, they do not have an incentive to increase prices and would therefore not act on any market power they possess. ${ }^{6}$

To estimate the hourly residual demand for fossil fuel generators, we first estimate the inverse supply equation for non-strategic firms. Specifically, we estimate:

$$
Q_{n s}=f\left(P, Z, N, \beta, \varepsilon_{n s}\right)
$$

where $P$ is the wholesale price, $Z$ is a vector of cost variables and $N$ is a vector variables that capture the native load of out-of-state firms, $\beta$ is a vector of unknown parameters and $\varepsilon_{n s}$ is a mean zero error term that captures unobserved components of non-strategic supply. ${ }^{7}$

Letting $Q_{t o t}$ be the amount of electricity demanded (perfectly inelastic), the residual demand faced by strategic firms can be expressed as:

\footnotetext{
${ }^{6}$ As such, we treat PG\&E's fossil fuel capacity as non-strategic. In addition, we treat the fossil fuel capacity listed under "other" as non-strategic. This capacity is largely "qualifying facitilty" units that are paid outside of the auction. As such, they do not have an incentive to act on any market power these might possess.

${ }^{7}$ Out-of-state IOUs are obligated to first service their own demand ("native load"). Therefore, increases in their native load implies, at a given price, less electricity is available to export to California.
} 


$$
\begin{aligned}
Q_{s} & =Q_{t o t}-Q_{n s} \\
& =Q_{t o t}-f\left(P, X, Z, \beta, \varepsilon_{n s}\right)
\end{aligned}
$$

\section{Results}

\subsection{Non-Strategic Functional Form, Variables and Results}

In this section we discuss the assumed functional form for non-strategic supply as well as the variables included on the right hand side. Table 3 reports the summary statistics for the variables and their correlation with non-strategic supply.

We allow the wholesale price to affect non-strategic supply differently during peak, offpeak and weekend periods. ${ }^{8}$ In addition, we interact these three prices with year indicator variables for the 3 years of data to capture changes in the behavior of non-strategic firms. This yields nine coefficients associated with the wholesale price. The wholesale price is likely to be endogenous since shocks to non-strategic supply decisions will influence the wholesale price. Fortunately, good demand instruments are available. Specifically, we instrument for price using the ISO's forecast for demand, which is independent of the error term since these forecasts do not take price into consideration. Given the interaction terms associated with price, we create nine instruments by interacting the forecasted load with the peak, off-peak, weekend and year indicator variables. Although we estimate non-strategic supply within a GMM framework, the results of the "first stage" regression of the PX price on forecasted load are presented Table 4; forecasted load is highly significant in each of the specifications.

The vector $X$ includes variables that capture the marginal cost of non-strategic supply. The bulk of non-strategic supply is generated using natural gas and hydroelectric resources. $P_{N}^{N G}$ and $P_{S}^{N G}$ are the daily city-gate price of natural gas for northern and southern California, respectively. While many of the non-strategic suppliers are out-of-state firms, regional natural gas prices are highly correlated. We control for the availability of hydroelectric resources using year and month indicator variables.

A key determinant of an out-of-state firm's ability to export power to California is their native load requirements. Many of the out-of-state firms are IOUs that are obligated to first meet their native loads; generation capacity in excess of the native load can be exported

\footnotetext{
${ }^{8}$ We define the peak period as those hours between $12 \mathrm{pm}$ and $6 \mathrm{pm}$.
} 
to California. To capture out-of-state native load requirements, we include the average of the minimum and maximum temperatures in Phoenix and Tucson in AZ, Portland and Pendleton in OR, Ely Yelland field and Las Vegas in NV, Salt Lake city in UT, Seattle and Spokane in WA. ${ }^{9}$ We also interact this variable with a summer indicator variable, since native demand is positively correlated with temperature during the summer-because of air conditioning - and negatively correlated with temperature during the winter - because of heating.

Finally, we include five sets of indicator variables to capture temporal changes in supply. We include a set of day of week, year, month, hour interacted with weekday and hour interacted with weekend dummies.

Reiss and Wolak (2003) illustrate that identifying $\theta$ hinges on the econometrician's assumptions regarding the function form of demand; the estimates of $\theta$ may vary widely depending on functional form assumptions. Therefore, we estimate three functional forms for non-strategic supply: a linear model, a log-log model and a linear-log model. ${ }^{10}$ The results from the three models of non-strategic load equation are reported in Table 5 . We estimate the equation using GMM and report Newey-West corrected standard errors that account for the serial correlation in the residuals. ${ }^{11}$

The results are largely consistent with economic intuition. In each of the three models, non-strategic supply is more responsive to price changes during the off-peak and weekend periods; this is likely because out-of-state firms have more excess capacity available throughout the different regions of their marginal cost curves. The sensitivity to price is not statistically different between 1998 and 1999, but decreased during 2000. This decrease is dramatic for the linear model, when non-strategic supply was much more inelastic. The results also suggest that higher natural gas prices reduce the supply of non-strategic generators; this effect is stronger for southern California natural gas prices. This may be because the majority of non-strategic plants that operate on natural gas are located in Arizona. Finally, higher out-of-state temperatures during the summer months decrease non-strategic supply, while this effect is reversed in fall, winter and spring.

The non-strategic supply curve estimates define the residual demand faced by in-state suppliers. Table 6 reports the mean, median and standard deviation of the residual demand

\footnotetext{
${ }^{9}$ The results are robust to a number of alternatives to simple averaging the maximum and minimum temperatures.

${ }^{10}$ That is, $y=\log (X) \beta+\varepsilon$.

${ }^{11}$ We include 24 lags.
} 
elasticity estimates. The estimated elasticities vary widely across the models. Residual demand is estimated to be much more inelastic when non-strategic supply is linear (implying a linear residual demand). The log-log and linear-log models largely agree.

\subsection{Direct Measures of Mark-ups}

Using the residual demand estimates, we calculate the hourly Lerner index and elasticityadjusted Lerner index for the three models; the descriptive statistics are reported in Table 7. For the entire sample, the average Lerner index is 0.13 . The elasticity-adjusted Lerner indexes widely agree across the three models. The average elasticity-adjusted Lerner index ranges from 0.070 to 0.073 , which is equivalent to a static equilibrium with 14 symmetric Cournot firms, far more than the 5 strategic firms that operate in California.

To see if there are temporal changes in the level of mark-ups, Table 7 also reports the Lerner index and elasticity-adjusted Lerner index during weekday peak, weekday off-peak and weekend periods and broken up by year. The average Lerner index increased significantly in 2000, compared to both 1998 and 1999. Interestingly, however, the average adjusted Lerner index shows little variation across the three years. The log-log and linear-log models suggest that market power levels increased slightly in 2000, but not nearly as much as the unadjusted Lerner Index.

Both adjusted and non-adjusted Lerner indexes are higher during peak hours. The average Lerner index during weekday off-peak periods is higher than weekend periods; for the linear and linear-log models, this relationship is reversed for adjusted Lerner indexes.

\subsection{Strategic Supply}

Given residual demand estimates, the strategic supply relationship is estimated from the first order condition in equation (4). Marginal costs are parameterized as a linear function of natural gas prices, $N O_{x}$ permit prices and a quadratic function of quantity.

$$
M C=\psi_{0}+\psi_{1} P_{P G E}^{N G}+\psi_{2} P_{S C E}^{N G}+\psi_{2} P_{S D G \& E}^{N G}+\psi_{4} P^{N O x}+\psi_{5} \text { Crisis } \times P^{N O x}+\psi_{6} q_{s t}+\psi_{7} q_{s t}^{2}
$$

Table 8 reports the strategic supply estimates for the three models of residual demand. The estimates of the average elasticity-adjusted Lerner index vary considerably across the three models. In the linear model the estimates is 0.063 (compared to the actual of 0.070 ), 
while in the log-log and linear-log models market power is overestimated, 0.226 and 0.162 , respectively. ${ }^{12}$ These results suggest that the NEIO does not provide robust estimates of market power levels. Given that the true functional form of demand is rarely known, these results suggest that the NEIO estimates are not reliable measures of market power.

Marginal costs are estimated to be convex in quantity. Given the high degree of multicollinearity with the natural gas prices, it is not surprising that only one of the prices is positive and significant (the SCE price). To account for the collinearity we interpret the natural gas variables as if each price increased by one dollar. A one dollar change in the price of natural gas for all three utilities results in a 7.7 dollar increase in marginal costs; this is consistent with engineering estimates. The coefficients with respect to the price of $N O_{x}$ permits are puzzling. Increases in the price of permits are estimated to reduce marginal costs. During the crisis period this effect subsided, but remains negative.

To test further the accuracy of the NEIO technique in estimating marginal costs, Table 9 reports the summary statistics of the direct measure of marginal cost minus the NEIO estimate for the linear model, while Figure 4 is a density estimate of this difference. ${ }^{13}$ The density estimate shows that in certain hours the NEIO estimate of MC is much greater than actual MC, while the NEIO does not understate MC by large amounts. On average, the NEIO technique underestimates marginal costs; however this is not symmetric. A regression of the direct measure of marginal cost on the NEIO estimates yields:

$$
M C_{t}^{N E I O}=-15.73+1.56 M C_{t}^{\text {Direct }}+\varepsilon_{t}
$$

Thus, the NEIO technique tends to understate marginal cost when marginal cost is low, but overstate marginal cost when it is high; this can be seen from Figure 5. In high demand periods, the quadratic marginal cost estimates overstate actual marginal costs. Strangely, the NEIO estimates suggest marginal costs initially decrease with quantity. In this region, the NEIO under-estimates marginal costs, but over-estimates marginal costs for high quantities.

As a second metric for the marginal cost estimates, we regress the direct measure of marginal cost on the cost shifters included in the NEIO technique. These results are reported

\footnotetext{
${ }^{12}$ We have also estimated the model assuming linear marginal costs. The estimated value of elasticityadjusted mark-ups (in the linear non-strategic supply case) is .103. The overestimate of mark-ups is not surprising since marginal costs during high demand periods are underestimated with the linear functional form.

${ }^{13}$ We chose the linear model since this yields the most accurate estimate of market power.
} 
in the first column of Table 10. Comparing these to the NEIO technique, we find that the NEIO technique does a poor job of estimating the sensitivity of marginal cost to cost shifters. Again, we use the linear model since this yields the most accurate estimates of marginal cost, on average. Both regressions suggest that the SCE natural gas price is most important in driving industry marginal cost; in addition, a one dollar increase of all three natural gas prices results in a 8.8 dollar increase in marginal cost, roughly in-line with the NEIO estimates. In contrast, the direct measure of marginal cost suggest that $N O_{x}$ permit prices have a positive and effect on marginal costs; this is statistically significant during the crisis period. This is not the case in the NEIO results. Finally, the direct measure of marginal cost is more convex in quantity than the NEIO results would suggest.

The next thought experiment we conduct is the following: suppose the econometrician knew the sensitivity of marginal cost to a specific input, possibly because of an engineering study, would the estimate of market power become more accurate? We do this for each of the models estimated. Tables 12 through 14 report the results. For variables denoted as "known" we replace the unknown marginal cost parameter with the marginal cost parameter estimated using the direct measures of marginal cost listed in the first column of Table 10. In general, this does not improve the accuracy of the estimated elasticity-adjusted Lerner index.

\subsubsection{Time-Varying Mark-Ups}

We next analyze whether the degree of mark-ups changes over time. We allow for two such changes: different mark-ups across years and different mark-ups throughout the day. Electricity prices during 2000 were certainly higher than in 1998 and 1999; however, there are a number of possible explanations for this increase. For one, costs may have increased. Second, the elasticity of residual demand may have fallen. Finally, market power levels may have increased, thus increasing the elasticity-adjusted Lerner index. Rows 2 through 4 of Table 7 summarizes the actual elasticity-adjusted Lerner index by year, as well as the standard Lerner index. The standard Lerner index illustrates that mark-ups increased dramatically between 1998/1999 and 2000. Interestingly, the elasticity-adjusted Lerner index suggests the change in mark-ups was the result of a decrease in the elasticity of demand; the adjusted mark-ups are not dramatically higher during 2000 compared to 1998 and 1999 .

The NEIO estimates of mark-ups for the different years are reported in Table 9; the results contrast with the actual measures of mark-ups. The NEIO technique suggests that market 
power was significantly higher in 2000. In the linear and linear-log models, the estimate of $\theta$ is significant only in 2000, while the log-log model suggests that market power existed in 1999 and 2000. The inability of the NEIO technique to accurately estimate changes in market power is important, since it could be the case that it does not estimate market power levels accurately, but policy makers can still learn about changes in market power levels. Unfortunately, this does not appear to be the case.

In the second alternative specification, we estimate a different $\theta$ during the peak hours of a weekday, the off-peak hours of a weekday and during weekends. The actual mark-levels are reported in rows 5 through 7 of Table 7 . The actual value of mark-ups suggest that after controlling for the elasticity of demand, mark-ups are highest during peak periods, while market power levels during off-peak hours and weekends are similar. The average adjusted mark-up during peak periods is .092, while it is .054 during off-peak periods; the average mark-up during weekends is .068. The estimated mark-ups are reported in Table 10. Each of the models suggest that market power levels are highest during the weekend, at odds with the actual measures.

\section{Robustness Checks}

In the above specifications, marginal costs are assumed to be quadratic in the quantity. However, Figure 4 suggests that this does a poor job representing actual marginal costs. Our first robustness check alters the functional form for marginal cost. We assume that marginal costs are a linear spline with one knot. We endogenously determine the knot by using the method in Andrews (1993). We estimate the endogenous spline model under the linear non-strategic supply model since this model provided the most accurate estimates of market power, as such we would like to know whether these accurate estimates are robust to other functional forms for marginal cost. The results are listed in Table 15. The results are nearly identical to the quadratic marginal cost model.

One shortcoming of our data is that in a substantial number of hours our marginal cost measure is above the market clearing price. This most likely occurs because Borenstein, Bushnell and Wolak do not consider the dynamic decision making of the firms. In the previous analysis we adjust the hourly marginal cost numbers to be the minimum of the Borenstein, Bushnell and Wolak measure and price. In this section, we adjust our sample such that this is less of an issue. In particular, we look at three sub-samples of the data. The 
first uses only those observations where price is observed to be greater than marginal cost. In this case, the shadow cost of shutting down a plant in hour $t$ and incurring a start up cost in hour $t+k$ will be zero. ${ }^{14}$ In the second sub-sample, we use only data from weekday peak hours. In this sub-sample, marginal cost exceeds price in only 21 percent of the observations. Finally, we restrict our sample to hours 11 through 21, where price is above marginal cost 22 percent of the time.

Tables 16, 18 and 20 report the actual measures of market power from using only those observations for which the price is above marginal cost, only weekday peak hours and only hours 11 through 21 to estimate the strategic supply curve, respectively. Tables 17, 19 and 21 report the NEIO estimates. These sub-samples further question the NEIO technique. Using the sample of observations for which the price is above marginal costs, the log-log and linear-log models provide the most accurate estimates of average market power, but all of the models continue to mis-measure intertemporal changes in market power levels. Using the weekday peak and hours 11-21 observations suggest that the linear model performs the best in estimating average market power levels, but does not capture inter-year variations.

\section{Conclusions}

In this paper we have compared actual measures of mark-ups and marginal costs to estimates based on the static conjectural variations first-order conditions of an industry. We take advantage of unique data that allow us to directly measure mark-ups in the restructured California electricity market and compare these mark-ups to those estimated by NEIO techniques. Our results suggest that, in this setting, the NEIO technique is not robust to functional form changes to demand. We also find that the NEIO estimates of marginal cost do not measure the sensitivity of marginal cost to cost shifters well. These results support Corts' (1999) theoretical critique of NEIO methods.

The results have clear policy implications. The first is that policy makers should be wary of relying on NEIO techniques to form policy. In our setting, it would be impossible to reliably estimate market power even if the true functional form for demand was known, since a priori one cannot determine which functional form is giving the correct estimates of market power. This is despite the robustness of actual market power to these functional form changes. Second, these results underline the importance of data collection requirements in

\footnotetext{
${ }^{14}$ One disadvantage of this is that we are truncating our residual.
} 
restructured electricity markets. Given that the NEIO does a poor job in this setting, future policy based on market power concerns will require actual marginal cost data. 


\section{References}

[1] Andrews, Donald W. K. "Tests for Parameter Instability and Structural Change With Unknown Change Point," Econometrica, 61(4), July 1993, pp. 821-856.

[2] Appelbaum, E. "The Estimation of the Degree of Oligopoly Power." Journal of Econometrics, 19(2-3), August 1982, pp. 287-99.

[3] Berg, Sigbjorn Atle and Moshe Kim. "Oligopolistic Interdependence and the Structure of Production in Banking: An Empirical Evaluation." Journal of Money, Credit, and Banking 26(2), May 1994, pp. 309-322.

[4] Brander James A. and Zhang, Anming. "Market Conduct in the Airline Industry: An Empirical Investigation" Rand Journal of Economics 21(4), Winter 1990, pp. 567-583.

[5] Brander James A. and Zhang, Anming. "Dynamic Oligopoly Behaviour in the Airline Industry," International Journal of Industrial Organization 11(3), September 1993, pp. 407-435.

[6] Bresnahan, T. F. "Empirical Studies of Industries with Market Power." In R. Schmalensee and R.D. Willig, eds., The Handbook of Industrial Organization. New York: North-Holland, 1989, pp. 1011-57.

[7] Borenstein, James B. Bushnell, and Christopher R. Knittel. "Market Power in Electricity Markets: Beyond Concentration Measures." The Energy Journal 20(4), October 1999, pp. 65-88.

[8] Borenstein, Severin, James B. Bushnell, Christopher R. Knittel, and Catherine D. Wolfram. "Trading Inefficiencies in California's Electricity Markets." POWER working Paper PWP-086, University of California, 2001.

[9] Borenstein, Severin, James B. Bushnell and Frank Wolak. "Measuring Market Inefficiencies in California's Restructured Wholesale Electricity Market." American Economic Review 92(5), December 2002, pp. 1376-1405.

[10] Clay, K. and Troesken, W. "Further Tests of Static Oligopoly Models: Whiskey, 18821898." The Journal of Industrial Economics LI(2), June 2003, pp. 151-166. 
[11] Corts, K.S. "Conduct Parameters and the Measurement of Market Power." Journal of Econometrics 88(2), February 1999, pp. 227-50.

[12] Diewert, W. E. and T. J. Wales. "Flexible Functional Forms and Global Curvature Conditions." Econometrica 55(1), January 1987, pp. 43-68.

[13] Ellison, Glenn. "Theories of Cartel Stability and the Joint Executive Committee." RAND Journal of Economics 25(1) Spring 1994, pp. 37-57.

[14] Gelfand, Matthew D. and Spiller, Pablo T. "Entry Barriers and Multiproduct Oligopolies: Do They Forebear or Spoil?" International Journal of Industrial Organization 5(1). March 1987, pp. 101-13

[15] Genesove, David and Wallace Mullin. "Testing Static Oligopoly Models: Conduct and Cost in the Sugar Industry, 1890-1914." Rand Journal of Economics 29(2), Summer 1994, pp. 355-377.

[16] Gollop, F. and Roberts, M. "Firm Interdependence in Oligopolistic Markets." Journal of Econometrics 1(3), August 1979, pp. 313-31.

[17] Joskow, Paul and Kahn, Ed. "A Quantitative Analysis of Pricing Behavior in California's Wholesale Electricity Market during Summer 2000." Energy Journal 23(4), October 2002, pp. 1-35.

[18] Kadiyali, Vrinda. "Exchange Rate Pass-through for Strategic Pricing and Advertising: An Empirical Analysis of the U.S. Photographic Film Industry." Journal of International Economics 43(3-4), November 1997, pp. 437-461.

[19] Kadiyali, Vrinda, Vilcassim, Naufel, and Chintagunta, Pradeep. "Product Line Extensions and Competitive Market Interactions: An Empirical Analysis." Journal of Econometrics 89(1-2), March-April 1999, pp. 339-363.

[20] Knittel, Christopher and Dae-Wook Kim. "A Note on the Market Power of California Electricity Firms during the Crisis." mimeo, UC Davis, 2004.

[21] Kolstad, C. and Turnovsky, M. "Cost Functions and Nonlinear prices: Estimating a Technology with Quality-Differenciated Inputs." The Review of Economics and Statistics 80(3), August 1998, pp. 444-453. 
[22] Lindh, Thomas. "The Inconsistency of Consistent Conjectures: Coming Back to Cournot." Journal of Economic Behavior and Organization 18(1), June 1992, pp. 69-90.

[23] Nebesky, William, McMullen, B. Starr, and Lee, Man-Keung. "Testing for Market Power in the U.S. Motor Carrier Industry." Review of Industrial Organization 10(5), October 1995, pp. 559-576.

[24] Natural Gas Intelligence, "NGI's Daily Gas Historical Data. 1998-2000.”

[25] Parker, P. and Röller, L. "Collusive Conduct in Duopolies: Multimarket Contact and Cross-Ownership in the Mobile Telephone Industry." Rand Journal of Economics 28(2), Summer 1997, pp. 304-322.

[26] Porter, R. H. "A Study of Cartel Stability: The Joint Executive Committee, 1880-1886." BELL Journal of Economics 14(2) Autumn 1983, pp. 301-314

[27] Puller, Steve. "Pricing and Firm Conduct in California Deregulated Electricity Market." POWER working paper PWR-080, University of California, 2001.

[28] Raper, Kellie Curry, Love, Alan H., and Shumway, Richard C.. "Determining Market Power Exertion between Buyers and Sellers." Journal of Applied Econometrics 15(3), May-June 2000, pp. 225-252.

[29] Reiss, Peter and Wolak, Frank. "Structural Econometric Modeling: Rationales and Examples From Industrial Organization." mimeo, Stanford University.

[30] Roberts, Mark J. "Testing Oligopolistic Behavior: An Application of the Variable Profit Function." Internation Journal of Industrial Organization 2(4), December 1984, pp. $367-383$.

[31] Röller, L. "Proper Quadratic Cost Function with an Application to the Bell System." The Review of Economics and Statistics 72(2), May 1990, pp. 202-210.

[32] Rotemberg, Julio J. and Saloner, Garth. "A Supergame-Theoretic Model of Price Wars during Booms." American Economic Review 76(3), June 1986, pp. 390-407.

[33] Rubinovitz, R. "Market Power and Price Increases for Basic Cable Service Since Deregulation." The RAND Journal of Economics 24(1), Spring 1993, pp. 1-18. 
[34] Spiller, Pablo T., and Favaro, Edgardo. "The Effects of Entry Regulation on Oligopolistic Interaction: The Uruguayan Banking Sector." Rand Journal of Economics 15(2). Summer 1984, pp. 244-54.

[35] Wolak, F. "Identification and Estimation of Cost functions Using Observed Bid Data: an Application to Electricity Markets." Working Paper 8191, National Bureau of Economics Research (2000).

[36] Wolfram, Catherine D. "Measuring Duopoly Power in the British Electricity Spot Market." American Economic Review 89(4), September 1999, pp. 805-826. 


\section{A Tables}

Table 1: Previous Studies

\begin{tabular}{cccccc}
\hline \hline \multicolumn{2}{c}{ Genesove and Mullin } & \multicolumn{2}{c}{ Wolfram } & \multicolumn{2}{c}{ Clay and Troesken } \\
\hline \hline Estimate & Actual & Estimate & Actual & Estimate & Actual \\
\hline \hline 0.038 & 0.107 & 0.012 & 0.052 & 0.173 & 0.086 \\
$(0.024)$ & $(0.028)$ & $(0.044)$ & Not reported & $(0.046)$ & $(0.054)$ \\
\hline
\end{tabular}

Linear functional form results for Genesove and Mullin (1998),

Wolfram (1999), and Clay and Troesken (2003)

Table 2: In-state Capacity during July 1999

\begin{tabular}{lcccc}
\hline \hline Firm & Fossil & Hydro & Nuclear & Renewable \\
\hline \hline AES & 4,071 & 0 & 0 & 0 \\
Duke & 2,950 & 0 & 0 & 0 \\
Dynegy & 2,856 & 0 & 0 & 0 \\
PG\&E & 580 & 3,878 & 2,160 & 793 \\
Reliant & 3,531 & 0 & 0 & 0 \\
SCE & 0 & 1,164 & 1,720 & 0 \\
Mirant & 3,424 & 0 & 0 & 0 \\
Other & 6,617 & 5,620 & 430 & 4,267 \\
\hline
\end{tabular}

Table 3: Summary Statistics of Non-Strategic Supply Variables

\begin{tabular}{lccccc}
\hline \hline & Mean & Std Dev & Min & Max & Corr $\left(X, Q_{n s}\right)$ \\
\hline \hline Price & 45.343 & 58.268 & 0 & 749.996 & 0.208 \\
NaturalGas $^{N}$ & 2.993 & 1.093 & 1.810 & 6.840 & -0.173 \\
NaturalGas $^{S}$ & 2.888 & 1.176 & 1.650 & 7.260 & -0.168 \\
Temperature $_{\text {Temperature } \times \text { Sum }}$ & 60.275 & 13.562 & 21.056 & 86.667 & 0.176 \\
\hline
\end{tabular}




\section{A.1 Results}

Table 4: First Stage Regressions

\begin{tabular}{|c|c|c|c|c|}
\hline & Price & $P \times W D a y \times P k$ & $P \times W d a y \times O P k$ & $P \times W e n d$ \\
\hline \multicolumn{5}{|l|}{ Full Sample } \\
\hline \multirow[t]{2}{*}{ Constant } & -104.883 & -341.787 & -70.107 & -73.929 \\
\hline & $(10.584)$ & $(55.836)$ & $(10.133)$ & $(12.275)$ \\
\hline \multirow[t]{2}{*}{ Forecast } & 0.006 & & & \\
\hline & $(0.000)$ & & & \\
\hline \multirow[t]{2}{*}{ Forecast $\times W D a y \times P k$} & & 0.013 & & \\
\hline & & $(0.002)$ & & \\
\hline \multirow[t]{2}{*}{ Forecast $\times W$ Day $\times O P k$} & & & 0.004 & \\
\hline & & & $(0.000)$ & \\
\hline \multirow[t]{2}{*}{ Forecast $\times$ Wend } & & & & 0.005 \\
\hline & & & & $(0.001)$ \\
\hline$-N-$ & 21214 & 4340 & 10540 & 6334 \\
\hline $\operatorname{Adj} R^{2}$ & 0.276 & 0.398 & 0.219 & 0.289 \\
\hline \multicolumn{5}{|l|}{1999 Sample } \\
\hline \multirow[t]{2}{*}{ Constant } & & -79.308 & -13.066 & -21.819 \\
\hline & & $(15.796)$ & $(1.787)$ & $(3.064)$ \\
\hline \multirow[t]{2}{*}{ Forecast $\times W D a y \times P k$} & & 0.004 & & \\
\hline & & $(0.001)$ & & \\
\hline \multirow[t]{2}{*}{ Forecast $\times W$ Day $\times O P k$} & & & 0.002 & \\
\hline & & & $(0.000)$ & \\
\hline \multirow[t]{2}{*}{ Forecast $\times W$ End } & & & & 0.002 \\
\hline & & & & $(0.000)$ \\
\hline$-\mathrm{N}-$ & & 1792 & 4352 & 2615 \\
\hline Adj $R^{2}$ & & 0.429 & 0.359 & 0.369 \\
\hline \multicolumn{5}{|l|}{2000 Sample } \\
\hline \multirow[t]{2}{*}{ Constant } & & -673.504 & -136.659 & -140.453 \\
\hline & & $(76.773)$ & $(19.183)$ & $(20.642)$ \\
\hline \multirow[t]{2}{*}{ Forecast $\times W$ Day $\times P k$} & & 0.024 & & \\
\hline & & $(0.003)$ & & \\
\hline \multirow[t]{2}{*}{ Forecast $\times W$ Day $\times O P k$} & & & 0.008 & \\
\hline & & & $(0.001)$ & \\
\hline \multirow[t]{2}{*}{ Forecast $\times$ WeekEnd } & & & & 0.008 \\
\hline & & & & $(0.001)$ \\
\hline$-\mathrm{N}-$ & & 1498 & 3638 & 2183 \\
\hline $\operatorname{Adj} R^{2}$ & & 0.655 & 0.339 & 0.444 \\
\hline Notes: All estimates are $s$ & icant & 6 level. & & \\
\hline
\end{tabular}


Table 5: Estimates of the Non-Strategic Supply Relationship

\begin{tabular}{|c|c|c|c|}
\hline & Linear & Log-log & Linear-log \\
\hline \multirow[t]{2}{*}{$P \times W d a y \times P k$} & $67.718^{* * *}$ & $0.159^{* * *}$ & $3878.3^{* * *}$ \\
\hline & $(7.849)$ & $(0.011)$ & $(261.1)$ \\
\hline \multirow[t]{2}{*}{$P \times W d a y \times O f f P k$} & $106.053^{* * *}$ & $0.195^{* * *}$ & $4333.0^{* * *}$ \\
\hline & $(13.547)$ & $(0.017)$ & $(377.1)$ \\
\hline \multirow[t]{2}{*}{$P \times W e n d$} & $149.387^{* * *}$ & $0.216^{* * *}$ & $4967.6^{* * *}$ \\
\hline & $(15.319)$ & $(0.016)$ & $(371.0)$ \\
\hline \multirow[t]{2}{*}{$P \times W d a y \times P k \times Y r 99$} & 11.169 & -0.008 & -12.466 \\
\hline & $(8.614)$ & $(0.012)$ & $(267.6)$ \\
\hline \multirow[t]{2}{*}{$P \times W d a y \times O f f P k \times Y r 99$} & 11.951 & -0.011 & -81.389 \\
\hline & $(10.867)$ & $(0.013)$ & $(286.9)$ \\
\hline \multirow[t]{2}{*}{$P \times W e n d \times Y r 99$} & 3.410 & 0.010 & -82.448 \\
\hline & (13.207) & $(0.012)$ & $(284.2)$ \\
\hline \multirow[t]{2}{*}{$P \times W d a y \times P k \times Y r 0$} & $-52.560^{* * *}$ & $-0.014^{* *}$ & -340.651 \\
\hline & $(7.686)$ & $(0.012)$ & $(254.9)$ \\
\hline \multirow[t]{2}{*}{$P \times W d a y \times O f f P k \times Y r 00$} & $-83.027^{* * *}$ & $-0.026^{* * *}$ & $-534.106^{* *}$ \\
\hline & $(12.165)$ & $(0.012)$ & $(279.4)$ \\
\hline \multirow[t]{2}{*}{$P \times W e n d \times Y r 00$} & $-110.935^{* * *}$ & $-0.030^{* * *}$ & $-675.295^{* * *}$ \\
\hline & $(13.695)$ & $(0.012)$ & $(279.4)$ \\
\hline \multirow[t]{2}{*}{$P_{N}^{N G}$} & $-909.188^{* *}$ & $-0.178^{* *}$ & $-3121.9^{*}$ \\
\hline & $(473.2)$ & $(0.090)$ & $(1937.3)$ \\
\hline \multirow[t]{2}{*}{$P_{S}^{N G}$} & $-748.451^{*}$ & $-0.195^{* *}$ & $-5181.0^{* * *}$ \\
\hline & $(430.2)$ & $(0.085)$ & $(1846.0)$ \\
\hline \multirow[t]{2}{*}{ Temperature } & $39.335^{* * *}$ & $0.044^{* *}$ & $993.695^{* *}$ \\
\hline & $(10.787)$ & $(0.024)$ & $(520.5)$ \\
\hline \multirow[t]{2}{*}{ Temperature $\times$ Sum } & $-70.733^{* * *}$ & $-0.295^{* * *}$ & $-6613.4^{* * *}$ \\
\hline & $(22.870)$ & $(0.085)$ & (1960.3) \\
\hline
\end{tabular}

Day, year, month, hour $\times$ weekday and hour $\times$ weekend monthly indicator variables not reported. 
Table 6: Estimates of Residual Demand Elasticities

\begin{tabular}{lcccccc}
\hline \hline & \multicolumn{2}{c}{ Linear } & \multicolumn{2}{c}{ Log-Log } & \multicolumn{2}{c}{ Linear-Log } \\
\hline \hline Mean & Median & Mean & Median & Mean & Median \\
\hline \hline \multirow{2}{*}{1998} & 0.687 & 0.576 & 1.250 & 1.004 & 1.334 & 1.035 \\
& $(0.485)$ & & $(0.870)$ & & $(1.058)$ & \\
& 0.735 & 0.666 & 1.279 & 1.133 & 1.343 & 1.131 \\
1999 & $(0.391)$ & & $(0.693)$ & & $(0.850)$ & \\
& 0.983 & 0.884 & 1.493 & 1.246 & 1.608 & 1.241 \\
\multirow{2}{*}{2000} & $(0.490)$ & & $(0.921)$ & & $(1.125)$ & \\
& 0.300 & 0.266 & 0.938 & 0.633 & 1.001 & 0.653 \\
\multirow{2}{*}{ Weekday Peak } & $0.176)$ & & $(0.817)$ & & $(0.943)$ & \\
& 0.385 & 0.392 & 0.713 & 0.621 & 0.702 & 0.607 \\
Weekday Offpeak & 0.641 & 0.608 & 1.263 & 1.058 & 1.316 & 1.019 \\
& $(0.406)$ & & $(0.798)$ & & $(0.933)$ & \\
& 0.972 & 0.910 & 1.599 & 1.368 & 1.793 & 1.486 \\
Weekend & $(0.578)$ & & $(1.019)$ & & $(1.238)$ & \\
\hline
\end{tabular}

Numbers in parentheses represent standard deviations. 
Table 7: Direct Measures of Lerner and Adjusted Lerner Indexes

\begin{tabular}{|c|c|c|c|c|c|}
\hline & & Linear Model & Log-log Model & Linear-Log Model & \\
\hline & $\overline{L I}$ & Adj LI & Adj LI & $\operatorname{Adj}$ LI & $\mathbf{N}$ \\
\hline \multirow[t]{2}{*}{ Entire Sample } & 0.127 & 0.070 & 0.073 & 0.071 & 21214 \\
\hline & $(0.191)$ & $(0.138)$ & $(0.096)$ & $(0.090)$ & \\
\hline \multirow[t]{2}{*}{1998} & 0.097 & 0.065 & 0.068 & 0.062 & 5136 \\
\hline & $(0.163)$ & $(0.148)$ & $(0.101)$ & $(0.089)$ & \\
\hline \multirow[t]{2}{*}{1999} & 0.088 & 0.071 & 0.066 & 0.064 & 8759 \\
\hline & $(0.139)$ & $(0.138)$ & $(0.094)$ & $(0.089)$ & \\
\hline \multirow[t]{2}{*}{2000} & 0.196 & 0.071 & 0.085 & 0.085 & 7319 \\
\hline & $(0.237)$ & $(0.129)$ & $(0.094)$ & $(0.090)$ & \\
\hline \multirow[t]{2}{*}{ Weekday Peak } & 0.228 & 0.096 & 0.103 & 0.097 & 4340 \\
\hline & $(0.243)$ & $(0.147)$ & $(0.094)$ & $(0.083)$ & \\
\hline \multirow[t]{2}{*}{ Weekday Offpeak } & 0.107 & 0.057 & 0.066 & 0.063 & 10540 \\
\hline & $(0.167)$ & $(0.122)$ & $(0.092)$ & $(0.085)$ & \\
\hline \multirow[t]{2}{*}{ Weekend } & 0.093 & 0.073 & 0.064 & 0.065 & 6334 \\
\hline & $(0.162)$ & $(0.152)$ & $(0.099)$ & $(0.099)$ & \\
\hline
\end{tabular}

Numbers in parentheses represent standard deviations. 
Table 8: Strategic Pricing Relationship Estimates

\begin{tabular}{|c|c|c|c|}
\hline & Linear Model & Log-log Model & Linear-log model \\
\hline \multirow[t]{2}{*}{ Constant } & $23.972^{* * *}$ & $7.249^{* * *}$ & -0.086 \\
\hline & $(7.256)$ & $(2.583)$ & $(3.359)$ \\
\hline \multirow[t]{2}{*}{$P_{P G \& E}^{N a t G a s}$} & 1.214 & $7.779^{* * *}$ & 4.636 \\
\hline & $(5.899)$ & $(2.926)$ & $(3.294)$ \\
\hline \multirow[t]{2}{*}{$P_{S C E}^{N a t G a s}$} & $14.630^{*}$ & $-8.400^{* *}$ & 0.183 \\
\hline & $(8.176)$ & $(3.674)$ & $(4.239)$ \\
\hline \multirow[t]{2}{*}{$P_{S D G \& E}^{N a t G a s}$} & -8.120 & $6.135^{* * *}$ & 3.909 \\
\hline & $(5.993)$ & $(2.286)$ & $(2.562)$ \\
\hline \multirow[t]{2}{*}{$P^{N O_{x}}$} & $-5.008^{* * *}$ & 0.157 & -0.402 \\
\hline & $(1.420)$ & $(0.506)$ & $(0.475)$ \\
\hline \multirow[t]{2}{*}{$P^{N O_{x}} \times$ Crisis } & $4.814^{* * *}$ & -0.304 & 0.402 \\
\hline & $(1.234)$ & $(0.454)$ & $(0.437)$ \\
\hline \multirow[t]{2}{*}{ Quantity } & $-0.015^{* * *}$ & -0.003 & $-0.003^{* * *}$ \\
\hline & $(0.002)$ & $(0.002)$ & $(0.001)$ \\
\hline \multirow[t]{2}{*}{ Quantity $^{2}$} & $1.723 \times 10^{-6 * * *}$ & $3.969 \times 10^{-7 * *}$ & $5.205 \times 10^{-7 * * *}$ \\
\hline & $\left(2.170 \times 10^{-7}\right)$ & $\left(1.941 \times 10^{-7}\right)$ & $\left(1.638 \times 10^{-7}\right)$ \\
\hline \multirow[t]{2}{*}{$\theta$} & $0.063^{* * *}$ & $0.226^{* * *}$ & $0.162^{* * *}$ \\
\hline & $(0.013)$ & $(0.019)$ & $(0.019)$ \\
\hline
\end{tabular}

${ }^{*}$ denotes significant at the .1 level, ${ }^{* *}$ at the .05 level, and ${ }^{* * *}$ at the .01 level 
Table 9: Strategic Pricing Relationship Estimates - Yearly Variation in $\theta$

\begin{tabular}{|c|c|c|c|}
\hline & Linear Model & Log-log Model & Linear-log Model \\
\hline \multirow[t]{2}{*}{ Constant } & $32.306^{* * *}$ & $17.261^{* * *}$ & $21.642^{* * *}$ \\
\hline & $(8.158)$ & $(4.435)$ & $(6.409)$ \\
\hline \multirow[t]{2}{*}{$P_{P G \& E}^{N a t G a s}$} & 5.680 & $12.007^{* * *}$ & $11.425^{* * *}$ \\
\hline & $(6.263)$ & $(4.380)$ & $(4.542)$ \\
\hline \multirow[t]{2}{*}{$P_{S C E}^{N a t G a s}$} & $19.783^{* *}$ & $-15.632^{* * *}$ & $-12.617^{* *}$ \\
\hline & $(8.542)$ & $(4.905)$ & $(5.921)$ \\
\hline \multirow[t]{2}{*}{$P_{S D G \& E}^{N a t G a s}$} & $-19.729^{* * *}$ & $6.796^{* * *}$ & $5.867^{* *}$ \\
\hline & $(6.894)$ & $(2.304)$ & $(3.003)$ \\
\hline \multirow[t]{2}{*}{$P^{N O_{x}}$} & $-4.628^{* * *}$ & 0.101 & -0.286 \\
\hline & $(1.406)$ & $(0.529)$ & $(0.563)$ \\
\hline \multirow[t]{2}{*}{$P^{N O_{x}} \times$ Crisis } & $4.447^{* * *}$ & -0.234 & 0.325 \\
\hline & $(1.218)$ & $(0.471)$ & $(0.512)$ \\
\hline \multirow[t]{2}{*}{ Quantity } & $-0.014^{* * *}$ & $-0.004^{*}$ & $-0.008^{* * *}$ \\
\hline & $(0.002)$ & $(0.002)$ & $(0.002)$ \\
\hline \multirow[t]{2}{*}{ Quantity $^{2}$} & $1.766 \times 10^{-6 * * *}$ & $5.838 \times 10^{-7 * *}$ & $1.156 \times 10^{-6 * * *}$ \\
\hline & $\left(2.169 \times 10^{-7}\right)$ & $\left(2.590 \times 10^{-7}\right)$ & $\left(2.968 \times 10^{-7}\right)$ \\
\hline \multirow[t]{2}{*}{$\theta \times \operatorname{Yr} 98$} & -0.038 & 0.090 & -0.078 \\
\hline & $(0.023)$ & $(0.069)$ & $(0.064)$ \\
\hline \multirow[t]{2}{*}{$\theta \times \operatorname{Yr} 99$} & 0.017 & $0.124^{* *}$ & -0.022 \\
\hline & $(0.045)$ & $(0.054)$ & $(0.056)$ \\
\hline \multirow[t]{2}{*}{$\theta \times Y r 00$} & $0.058^{* * *}$ & $0.218^{* * *}$ & $0.122^{* * *}$ \\
\hline & $(0.013)$ & $(0.022)$ & $(0.029)$ \\
\hline
\end{tabular}

${ }^{*}$ denotes significant at the .1 level, ${ }^{* *}$ at the .05 level, and ${ }^{* * *}$ at the .01 level 
Table 10: Strategic Pricing Relationship Estimates-Intra-day Variation in $\theta$

\begin{tabular}{|c|c|c|c|}
\hline & Linear-log Model & Log-log Model & Linear-log Model \\
\hline \multirow[t]{2}{*}{ Constant } & $24.650^{* * *}$ & $14.257^{* * *}$ & 1.223 \\
\hline & $(7.440)$ & $(3.091)$ & $(1.490)$ \\
\hline \multirow[t]{2}{*}{$P_{P G \& E}^{N a t G a s}$} & 1.574 & $9.800^{* * *}$ & $7.084^{* * *}$ \\
\hline & $(5.811)$ & $(2.893)$ & $(2.033)$ \\
\hline \multirow{2}{*}{$P_{S C E}^{N a t G a s}$} & $14.772^{*}$ & $-15.296^{* * *}$ & $-7.919^{* * *}$ \\
\hline & $(8.015)$ & $(3.973)$ & $(2.518)$ \\
\hline \multirow[t]{2}{*}{$P_{S D G \& E}^{N a t G a s}$} & -9.080 & $8.872^{* * *}$ & $5.339^{* * *}$ \\
\hline & $(5.959)$ & $(2.388)$ & $(1.403)$ \\
\hline \multirow[t]{2}{*}{$P^{N O_{x}}$} & $-5.334^{* * *}$ & 0.668 & 0.132 \\
\hline & $(1.445)$ & $(0.537)$ & $(0.271)$ \\
\hline \multirow[t]{2}{*}{$P^{N O_{x}} \times$ Crisis } & $5.129^{* * *}$ & $-0.769^{*}$ & 0.013 \\
\hline & $(1.260)$ & $(0.470)$ & $(0.257)$ \\
\hline \multirow[t]{2}{*}{ Quantity } & $-0.014^{* * *}$ & $-0.004^{* *}$ & $0.002^{* * *}$ \\
\hline & $(0.002)$ & $(0.002)$ & $(0.001)$ \\
\hline \multirow[t]{2}{*}{ Quantity $^{2}$} & $1.700 \times 10^{-6 * * *}$ & $4.700 \times 10^{-7 * * *}$ & $-1.720 \times 10^{-7 * * *}$ \\
\hline & $\left(2.169 \times 10^{-7}\right)$ & $\left(1.835 \times 10^{-7}\right)$ & $\left(6.626 \times 10^{-8}\right)$ \\
\hline \multirow[t]{2}{*}{$\theta \times W d a y \times P k$} & $0.068^{* * *}$ & $0.221^{* * *}$ & $0.242^{* * *}$ \\
\hline & $(0.013)$ & $(0.017)$ & $(0.008)$ \\
\hline \multirow[t]{2}{*}{$\theta \times W d a y \times O f f P k$} & $0.059^{* * *}$ & $0.255^{* * *}$ & $0.260^{* * *}$ \\
\hline & $(0.012)$ & $(0.024)$ & $(0.010)$ \\
\hline \multirow[t]{2}{*}{$\theta \times W e n d$} & $0.092^{* * *}$ & $0.283^{* * *}$ & $0.308^{* * *}$ \\
\hline & $(0.018)$ & $(0.027)$ & $(0.011)$ \\
\hline
\end{tabular}


Table 11: Summary Statistics of Actual MC minus NEIO MC (linear model)

\begin{tabular}{ccccccc}
\hline \hline & Mean & Std Dev & Skew & Kurtosis & Min & Max \\
\hline \hline$M C-\widehat{M C}_{N E I O}$ & -2.00 & 29.27 & -2.44 & 10.71 & -201.41 & 202.28 \\
\hline
\end{tabular}

Table 12: Supplemental Information and Estimates of Market Power

Linear Model. For variables marked as known, their estimate from the Direct MC equation are used and treated as fixed.

\begin{tabular}{|c|c|c|c|c|c|}
\hline & Direct MC & NEIO 1 & NEIO 2 & NEIO 3 & NEIO 4 \\
\hline Constant & $\begin{array}{c}-7.200^{* * *} \\
(0.676)\end{array}$ & $\begin{array}{c}23.972^{* * *} \\
(7.256)\end{array}$ & $\begin{array}{c}21.832^{* * *} \\
(4.872)\end{array}$ & $\begin{array}{c}27.107^{* * *} \\
(7.726)\end{array}$ & $\begin{array}{c}-17.157^{\text {*** }} \\
(5.100)\end{array}$ \\
\hline$P_{P G \& E}^{N a t G a s}$ & $\begin{array}{l}0.944^{* *} \\
(0.423)\end{array}$ & $\begin{array}{c}1.214 \\
(5.899)\end{array}$ & known & $\begin{array}{l}-0.111 \\
(6.178)\end{array}$ & $\begin{array}{l}-7.888 \\
(7.010)\end{array}$ \\
\hline$P_{S C E}^{N a t G a s}$ & $\begin{array}{l}4.227^{* * *} \\
(1.235)\end{array}$ & $\begin{array}{l}14.630^{*} \\
(8.176)\end{array}$ & known & $\begin{array}{c}27.387^{* * *} \\
(8.463)\end{array}$ & $\begin{array}{l}66.134^{* * *} \\
(10.649)\end{array}$ \\
\hline$P_{S D G \& E}^{N a t G a s}$ & $\begin{array}{l}3.205^{* * *} \\
(1.065)\end{array}$ & $\begin{array}{l}-8.120 \\
(5.993)\end{array}$ & known & $\begin{array}{c}-21.580^{* * *} \\
(6.647)\end{array}$ & $\begin{array}{c}-45.083^{* * *} \\
(8.479)\end{array}$ \\
\hline$P^{N O_{x}}$ & $\begin{array}{c}0.128 \\
(0.103)\end{array}$ & $\begin{array}{c}-5.008^{* * *} \\
(1.420)\end{array}$ & $\begin{array}{c}-5.380^{* * *} \\
(1.443)\end{array}$ & known & $\begin{array}{c}-12.693^{* * *} \\
(1.536)\end{array}$ \\
\hline $\begin{array}{l}P^{N O_{x}} \\
\times \text { Crisis }\end{array}$ & $\begin{array}{c}0.098 \\
(0.099)\end{array}$ & $\begin{array}{l}4.814^{* * *} \\
(1.234)\end{array}$ & $\begin{array}{l}5.137^{* * *} \\
(1.302)\end{array}$ & known & $\begin{array}{c}11.689^{* * *} \\
(1.348)\end{array}$ \\
\hline Quantity & $\begin{array}{l}0.002^{* * *} \\
(0.000)\end{array}$ & $\begin{array}{c}-0.015^{* * *} \\
(0.003)\end{array}$ & $\begin{array}{c}-0.015^{* * *} \\
(0.002)\end{array}$ & $\begin{array}{c}-0.015^{* * *} \\
(0.003)\end{array}$ & known \\
\hline Quantity $^{2}$ & $\begin{array}{c}-6.52 \times 10^{-9} \\
\left(1.525 \times 10^{-8}\right)\end{array}$ & $\begin{array}{l}1.723 \times 10^{-6 * * *} \\
\left(2.170 \times 10^{-7}\right)\end{array}$ & $\begin{array}{l}1.735 \times 10^{-6 * * *} \\
\left(2.170 \times 10^{-7}\right)\end{array}$ & $\begin{array}{c}1.794 \times 10^{-6 * * *} \\
\left(2.263 \times 10^{-7}\right)\end{array}$ & known \\
\hline$\theta$ & $\begin{array}{c}0.070 \\
(0.138)^{\dagger}\end{array}$ & $\begin{array}{c}0.063^{* * *} \\
(0.013)\end{array}$ & $\begin{array}{c}0.061^{* * *} \\
(0.013)\end{array}$ & $\begin{array}{c}0.055^{* * *} \\
(0.011)\end{array}$ & $\begin{array}{c}0.130^{* * *} \\
(0.018)\end{array}$ \\
\hline
\end{tabular}


Table 13: Supplemental Information and Estimates of Market Power

Log-log Model. For variables marked as known, their estimate from the Direct MC equation are used and treated as fixed.

\begin{tabular}{|c|c|c|c|c|c|}
\hline & Direct MC & NEIO 1 & NEIO 2 & NEIO 3 & NEIO 4 \\
\hline \multirow[t]{2}{*}{ Constant } & $-7.200^{* * *}$ & $7.249^{* * *}$ & 3.353 & $13.814^{* * *}$ & -1.544 \\
\hline & $(0.676)$ & $(2.583)$ & $(3.187)$ & $(7.726)$ & $(2.312)$ \\
\hline \multirow[t]{2}{*}{$P_{P G \& E}^{N a t G a s}$} & $0.944^{* *}$ & $7.779^{* * *}$ & known & $6.145^{* *}$ & $6.487^{* * *}$ \\
\hline & $(0.423)$ & $(2.926)$ & & $(2.818)$ & $(2.681)$ \\
\hline \multirow[t]{2}{*}{$P_{S C E}^{N a t G a s}$} & $4.227^{* * *}$ & $-8.400^{* *}$ & known & $-14.699^{* * *}$ & -3.442 \\
\hline & $(1.235)$ & $(3.674)$ & & $(3.475)$ & $(3.147)$ \\
\hline \multirow[t]{2}{*}{$P_{S D G \& E}^{N a t G a s}$} & $3.205^{* * *}$ & $6.135^{* * *}$ & known & $11.790^{* * *}$ & 2.171 \\
\hline & $(1.065)$ & $(2.286)$ & & $(1.903)$ & $(2.083)$ \\
\hline \multirow[t]{2}{*}{$P^{N O_{x}}$} & 0.128 & 0.157 & -0.247 & known & 0.144 \\
\hline & $(0.103)$ & $(0.506)$ & $(0.454)$ & & $(0.472)$ \\
\hline$P^{N O_{x}}$ & 0.098 & -0.304 & -0.072 & known & -0.350 \\
\hline$\times$ Crisis & $(0.099)$ & $(0.454)$ & $(0.440)$ & & $(0.425)$ \\
\hline \multirow[t]{2}{*}{ Quantity } & $0.002^{* * *}$ & -0.003 & $-0.005^{* * *}$ & $-0.003^{*}$ & known \\
\hline & $(0.000)$ & $(0.002)$ & $(0.002)$ & $(0.002)$ & \\
\hline \multirow[t]{2}{*}{ Quantity $^{2}$} & $-6.52 \times 10^{-9}$ & $3.969 \times 10^{-7 * *}$ & $6.673 \times 10^{-7 * * *}$ & $4.694 \times 10^{-7 * *}$ & known \\
\hline & $\left(1.525 \times 10^{-8}\right)$ & $\left(1.941 \times 10^{-7}\right)$ & $\left(1.778 \times 10^{-7}\right)$ & $\left(2.193 \times 10^{-7}\right)$ & \\
\hline \multirow[t]{2}{*}{$\theta$} & 0.073 & $0.226^{* * *}$ & $0.186^{* * *}$ & $0.218^{* * *}$ & $0.247^{* * *}$ \\
\hline & $(0.096)^{\dagger}$ & $(0.019)$ & $(0.017)$ & $(0.020)$ & $(0.006)$ \\
\hline
\end{tabular}

$*$ denotes significant at the .1 level, ${ }^{* *}$ at the .05 level, and ${ }^{* * *}$ at the .01 level

$\dagger$ This represents the standard devation. 
Table 14: Supplemental Information and Estimates of Market Power

Linear-Log Model. For variables marked as known, their estimate from the Direct MC equation are used and treated as fixed.

\begin{tabular}{|c|c|c|c|c|c|}
\hline & Direct MC & NEIO 1 & NEIO 2 & NEIO 3 & NEIO 4 \\
\hline \multirow[t]{2}{*}{ Constant } & $-7.200^{* * *}$ & -0.086 & 0.530 & 3.910 & $-8.101^{* * *}$ \\
\hline & $(0.676)$ & $(3.359)$ & $(2.607)$ & $(2.775)$ & $(1.831)$ \\
\hline \multirow[t]{2}{*}{$P_{P G \& E}^{N a t G a s}$} & $0.944^{* *}$ & 4.636 & known & 3.696 & 3.840 \\
\hline & $(0.423)$ & $(3.294)$ & & $(3.445)$ & $(2.762)$ \\
\hline \multirow[t]{2}{*}{$P_{S C E}^{N a t G a s}$} & $4.227^{* * *}$ & 0.183 & known & -1.359 & 3.432 \\
\hline & $(1.235)$ & $(4.239)$ & & $(4.465)$ & $(3.390)$ \\
\hline \multirow[t]{2}{*}{$P_{S D G \& E}^{N a t G a s}$} & $3.205^{* * *}$ & 3.909 & known & $4.945^{* *}$ & 0.817 \\
\hline & $(1.065)$ & $(2.562)$ & & $(2.183)$ & $(1.905)$ \\
\hline \multirow[t]{2}{*}{$P^{N O_{x}}$} & 0.128 & -0.402 & -0.330 & known & -0.490 \\
\hline & $(0.103)$ & $(0.475)$ & $(0.404)$ & & $(0.387)$ \\
\hline$P^{N O_{x}}$ & 0.098 & 0.402 & 0.356 & known & 0.480 \\
\hline$\times$ Crisis & $(0.099)$ & $(0.437)$ & $(0.388)$ & & $(0.358)$ \\
\hline \multirow[t]{2}{*}{ Quantity } & $0.002^{* * *}$ & $-0.003^{* *}$ & $-0.003^{* *}$ & $-0.004^{* * *}$ & known \\
\hline & $(0.000)$ & $(0.001)$ & $(0.001)$ & $(0.001)$ & \\
\hline \multirow[t]{2}{*}{ Quantity $^{2}$} & $-6.52 \times 10^{-9}$ & $5.205 \times 10^{-7 * * *}$ & $5.202 \times 10^{-7 * * *}$ & $5.705 \times 10^{-7 * * *}$ & known \\
\hline & $\left(1.525 \times 10^{-8}\right)$ & $\left(1.638 \times 10^{-7}\right)$ & $\left(1.595 \times 10^{-7}\right)$ & $\left(1.644 \times 10^{-7}\right)$ & \\
\hline \multirow[t]{2}{*}{$\theta$} & 0.071 & $0.162^{* * *}$ & $0.162^{* * *}$ & $0.157^{* * *}$ & $0.201^{* * *}$ \\
\hline & $(0.090)^{\dagger}$ & $(0.019)$ & $(0.019)$ & $(0.020)$ & $(0.005)$ \\
\hline \multicolumn{6}{|c|}{$*$ denotes significant at the .1 level, ${ }^{* *}$ at the .05 level, and $* * *$ at the .01 level } \\
\hline$\dagger$ This re & ents the stan & ard devation. & & & \\
\hline
\end{tabular}




\section{A.2 Robustness Checks}

\section{A.2.1 Endogenous MC Spline}

Table 15: Strategic Pricing Relationship Estimates (Spline Function)

\begin{tabular}{|c|c|c|c|}
\hline & Model 1 & Model 2 & Model 3 \\
\hline Constant & $\begin{array}{c}-14.993^{* * *} \\
(3.612)\end{array}$ & $\begin{array}{c}-5.004^{* * *} \\
(4.615)\end{array}$ & $\begin{array}{c}-14.524^{* * *} \\
(3.741)\end{array}$ \\
\hline$P_{P G \& E}^{N a t G a s}$ & $\begin{array}{c}0.456 \\
(5.360)\end{array}$ & $\begin{array}{c}5.633 \\
(5.833)\end{array}$ & $\begin{array}{c}0.948 \\
(5.266)\end{array}$ \\
\hline$P_{S C E}^{N a t G a s}$ & $\begin{array}{c}28.819^{* * *} \\
(7.585)\end{array}$ & $\begin{array}{c}36.379^{* * *} \\
(8.342)\end{array}$ & $\begin{array}{c}28.632^{* * *} \\
(7.384)\end{array}$ \\
\hline$P_{S D G \& E}^{N a t G a s}$ & $\begin{array}{c}-19.277^{* * *} \\
(6.205)\end{array}$ & $\begin{array}{c}-34.927^{* * *} \\
(7.729)\end{array}$ & $\begin{array}{c}-19.744^{* * *} \\
(6.105)\end{array}$ \\
\hline$P^{N O_{x}}$ & $\begin{array}{c}-5.645^{* * *} \\
(1.448)\end{array}$ & $\begin{array}{c}-5.303^{* * *} \\
(1.429)\end{array}$ & $\begin{array}{c}-5.914^{* * *} \\
(1.474)\end{array}$ \\
\hline$P^{N O_{x}} \times$ Crisis & $\begin{array}{c}5.407^{* * *} \\
(1.262)\end{array}$ & $\begin{array}{c}5.062^{* * *} \\
(1.241)\end{array}$ & $\begin{array}{c}5.657^{* * *} \\
(1.287)\end{array}$ \\
\hline Spline 1 & $\begin{array}{l}0.003^{* * *} \\
(0.0004)\end{array}$ & $\begin{array}{l}0.004^{* * *} \\
(0.0006)\end{array}$ & $\begin{array}{l}0.003^{* * *} \\
(0.0004)\end{array}$ \\
\hline Spline 2 & $\begin{array}{c}0.029^{* * *} \\
(0.003)\end{array}$ & $\begin{array}{c}0.029^{* * *} \\
(0.003)\end{array}$ & $\begin{array}{c}0.029^{* * *} \\
(0.003)\end{array}$ \\
\hline$\theta$ & $\begin{array}{c}0.065^{* * *} \\
(0.014)\end{array}$ & & \\
\hline$\theta \times \operatorname{Yr} 98$ & & $\begin{array}{c}-0.065^{* * *} \\
(0.020)\end{array}$ & \\
\hline$\theta \times Y r 99$ & & $\begin{array}{l}-0.009 \\
(0.039)\end{array}$ & \\
\hline$\theta \times Y r 00$ & & $\begin{array}{c}0.059^{* * *} \\
(0.014)\end{array}$ & \\
\hline$\theta \times W d a y \times P k$ & & & $\begin{array}{c}0.071^{* * *} \\
(0.014)\end{array}$ \\
\hline$\theta \times W d a y \times O f f P k$ & & & $\begin{array}{c}0.058^{* * *} \\
(0.013)\end{array}$ \\
\hline$\theta \times W e n d$ & & & $\begin{array}{c}0.093^{* * *} \\
(0.019)\end{array}$ \\
\hline
\end{tabular}




\section{A.2.2 Selected Sample}

Table 16: Direct Measures of Lerner and Adjusted Lerner Indexes - Selected Sample

\begin{tabular}{|c|c|c|c|c|c|}
\hline & & Linear Model & Log-log Model & Linear-Log Model & \\
\hline & $\mathbf{L I}$ & $\operatorname{Adj} \mathbf{L I}$ & $\operatorname{Adj} \mathbf{L I}$ & $\operatorname{Adj} \mathbf{L I}$ & $\mathbf{N}$ \\
\hline \multirow[t]{2}{*}{ Entire Sample } & 0.228 & 0.125 & 0.130 & 0.126 & 11853 \\
\hline & $(0.205)$ & $(0.164)$ & $(0.094)$ & $(0.086)$ & \\
\hline \multirow[t]{2}{*}{1998} & 0.186 & 0.126 & 0.128 & 0.116 & 2671 \\
\hline & $(0.186)$ & $(0.186)$ & $(0.107)$ & $(0.093)$ & \\
\hline \multirow[t]{2}{*}{1999} & 0.174 & 0.141 & 0.130 & 0.126 & 4428 \\
\hline & $(0.153)$ & $(0.167)$ & $(0.095)$ & $(0.088)$ & \\
\hline \multirow[t]{2}{*}{2000} & 0.302 & 0.109 & 0.131 & 0.131 & 4754 \\
\hline & $(0.234)$ & $(0.146)$ & $(0.087)$ & $(0.080)$ & \\
\hline \multirow[t]{2}{*}{ Weekday Peak } & 0.287 & 0.121 & 0.129 & 0.122 & 3446 \\
\hline & $(0.240)$ & $(0.155)$ & $(0.088)$ & $(0.075)$ & \\
\hline \multirow[t]{2}{*}{ Weekday Offpeak } & 0.205 & 0.109 & 0.125 & 0.119 & 5529 \\
\hline & $(0.183)$ & $(0.151)$ & $(0.092)$ & $(0.083)$ & \\
\hline \multirow[t]{2}{*}{ Weekend } & 0.203 & 0.160 & 0.140 & 0.143 & 2878 \\
\hline & $(0.187)$ & $(0.192)$ & $(0.105)$ & $(0.101)$ & \\
\hline
\end{tabular}

Numbers in parentheses represent standard deviations. 
Table 17: Strategic Pricing Relationship Estimates-Selected Sample

\begin{tabular}{|c|c|c|c|}
\hline & Linear Model & Log-log Model & Linear-Log Model \\
\hline \multirow[t]{2}{*}{$\theta$} & $0.042^{* * *}$ & $0.166^{* * *}$ & $0.139^{* * *}$ \\
\hline & $(0.015)$ & $(0.036)$ & $(0.027)$ \\
\hline \multirow[t]{2}{*}{$\theta \times \operatorname{Yr} 98$} & $-0.084^{* * *}$ & 0.048 & -0.003 \\
\hline & $(0.031)$ & $(0.099)$ & $(0.068)$ \\
\hline \multirow[t]{2}{*}{$\theta \times \operatorname{Yr} 99$} & -0.026 & 0.088 & 0.039 \\
\hline & $(0.061)$ & $(0.072)$ & $(0.058)$ \\
\hline \multirow[t]{2}{*}{$\theta \times Y r 00$} & $0.034^{* *}$ & $0.155^{* * *}$ & $0.112^{* * *}$ \\
\hline & $(0.015)$ & $(0.043)$ & $(0.036)$ \\
\hline \multirow[t]{2}{*}{$\theta \times W d a y \times P k$} & $0.044^{* * *}$ & $0.168^{* * *}$ & $0.202^{* * *}$ \\
\hline & $(0.015)$ & $(0.036)$ & $(0.018)$ \\
\hline \multirow[t]{2}{*}{$\theta \times W d a y \times O f f P k$} & $0.034^{* *}$ & $0.193^{* * *}$ & $0.215^{* * *}$ \\
\hline & $(0.015)$ & $(0.047)$ & $(0.021)$ \\
\hline \multirow[t]{2}{*}{$\theta \times W e n d$} & $0.046^{* *}$ & $0.207^{* * *}$ & $0.247^{* * *}$ \\
\hline & $(0.023)$ & $(0.053)$ & $(0.024)$ \\
\hline
\end{tabular}




\section{A.2.3 Weekday Peak Observations}

Table 18: Direct Measures of Lerner and Adjusted Lerner Indexes-Weekday Peak

\begin{tabular}{lccccc}
\hline \hline & & Linear Model & Log-log Model & Linear-Log Model & \\
\hline \hline \multirow{2}{*}{ Entire Sample } & LI & Adj LI & Adj LI & Adj LI & N \\
\cline { 2 - 5 } 1998 & $(0.228$ & 0.096 & 0.103 & 0.097 & 4340 \\
& 0.214 & 0.108 & $(0.094)$ & $(0.083)$ & \\
\multirow{2}{*}{1999} & $(0.230)$ & $(0.162)$ & 0.113 & 0.103 & 1050 \\
& 0.172 & 0.094 & $(0.104)$ & $(0.089)$ & \\
2000 & $(0.187)$ & $(0.134)$ & 0.094 & 0.091 & 1792 \\
& 0.304 & 0.089 & $(0.088)$ & $(0.082)$ & \\
& $(0.287)$ & $(0.151)$ & 0.106 & 0.101 & 1498 \\
\hline
\end{tabular}

Numbers in parentheses represent standard deviations.

Table 19: Strategic Pricing Relationship Estimates-Weekday Peak

\begin{tabular}{|c|c|c|c|}
\hline & Linear Model & Log-log Model & Linear-Log Model \\
\hline \multirow[t]{2}{*}{$\theta$} & $0.079^{* * *}$ & $0.198^{* * *}$ & $0.167^{* * *}$ \\
\hline & $(0.030)$ & $(0.046)$ & $(0.021)$ \\
\hline \multirow[t]{2}{*}{$\theta \times \operatorname{Yr} 98$} & -0.036 & 0.010 & -0.091 \\
\hline & $(0.089)$ & $(0.155)$ & $(0.088)$ \\
\hline \multirow[t]{2}{*}{$\theta \times \operatorname{Yr} 99$} & 0.067 & 0.047 & -0.031 \\
\hline & $(0.188)$ & $(0.126)$ & $(0.077)$ \\
\hline \multirow[t]{2}{*}{$\theta \times Y r 00$} & $0.079^{* *}$ & $0.189^{* * *}$ & $0.134^{* * *}$ \\
\hline & $(0.038)$ & $(0.053)$ & $(0.033)$ \\
\hline
\end{tabular}




\section{A.2.4 Hour 11-21 Observations}

Table 20: Direct Measures of Lerner and Adjusted Lerner Indexes-Hours 11-21

\begin{tabular}{|c|c|c|c|c|c|}
\hline & & Linear Model & Log-log Model & Linear-Log Model & \\
\hline & $\mathbf{L I}$ & Adj LI & Adj LI & Adj LI & $\mathbf{N}$ \\
\hline \multirow[t]{2}{*}{ Entire Sample } & 0.198 & 0.108 & 0.107 & 0.100 & 9724 \\
\hline & $(0.225)$ & $(0.169)$ & $(0.104)$ & $(0.093)$ & \\
\hline \multirow[t]{2}{*}{1998} & 0.169 & 0.105 & 0.105 & 0.093 & 2354 \\
\hline & $(0.201)$ & $(0.164)$ & $(0.108)$ & $(0.091)$ & \\
\hline \multirow[t]{2}{*}{1999} & 0.149 & 0.114 & 0.104 & 0.099 & 4015 \\
\hline & $(0.169)$ & $(0.173)$ & $(0.105)$ & $(0.098)$ & \\
\hline \multirow[t]{2}{*}{2000} & 0.277 & 0.104 & 0.112 & 0.106 & 3355 \\
\hline & $(0.272)$ & $(0.167)$ & $(0.100)$ & $(0.088)$ & \\
\hline \multirow[t]{2}{*}{ Weekday Peak } & 0.228 & 0.096 & 0.103 & 0.097 & 4340 \\
\hline & $(0.243)$ & $(0.147)$ & $(0.094)$ & $(0.083)$ & \\
\hline \multirow[t]{2}{*}{ Weekday Offpeak } & 0.207 & 0.119 & 0.123 & 0.107 & 2480 \\
\hline & $(0.212)$ & $(0.171)$ & $(0.105)$ & $(0.086)$ & \\
\hline \multirow[t]{2}{*}{ Weekend } & 0.145 & 0.118 & 0.099 & 0.097 & 2904 \\
\hline & $(0.195)$ & $(0.195)$ & $(0.116)$ & $(0.110)$ & \\
\hline
\end{tabular}


Table 21: Strategic Pricing Relationship Estimates-Hour 11-21 observations

\begin{tabular}{|c|c|c|c|}
\hline & Linear Model & Log-log Model & Linear-Log Model \\
\hline \multirow[t]{2}{*}{$\theta$} & $0.065^{* * *}$ & $0.216^{* * *}$ & $0.167^{* * *}$ \\
\hline & $(0.020)$ & $(0.027)$ & $(0.021)$ \\
\hline \multirow[t]{2}{*}{$\theta \times \operatorname{Yr} 98$} & $-0.084^{* *}$ & 0.037 & -0.092 \\
\hline & $(0.044)$ & $(0.100)$ & $(0.088)$ \\
\hline \multirow[t]{2}{*}{$\theta \times Y r 99$} & -0.030 & 0.086 & -0.031 \\
\hline & $(0.080)$ & $(0.076)$ & $(0.077)$ \\
\hline \multirow{2}{*}{$\theta \times Y r 00$} & $0.057^{* * *}$ & $0.216^{* * *}$ & $0.134^{* * *}$ \\
\hline & $(0.021)$ & $(0.028)$ & $(0.033)$ \\
\hline \multirow[t]{2}{*}{$\theta \times W d a y \times P k$} & $0.074^{* * *}$ & $0.227^{* * *}$ & $0.241^{* * *}$ \\
\hline & $(0.021)$ & $(0.024)$ & $(0.009)$ \\
\hline \multirow[t]{2}{*}{$\theta \times W d a y \times O f f P k$} & $0.089^{* * *}$ & $0.272^{* * *}$ & $0.262^{* * *}$ \\
\hline & $(0.028)$ & $(0.030)$ & $(0.011)$ \\
\hline \multirow[t]{2}{*}{$\theta \times W e n d$} & $0.121^{* * *}$ & $0.288^{* * *}$ & $0.311^{* * *}$ \\
\hline & $(0.038)$ & $(0.039)$ & $(0.013)$ \\
\hline
\end{tabular}




\section{B Figures}

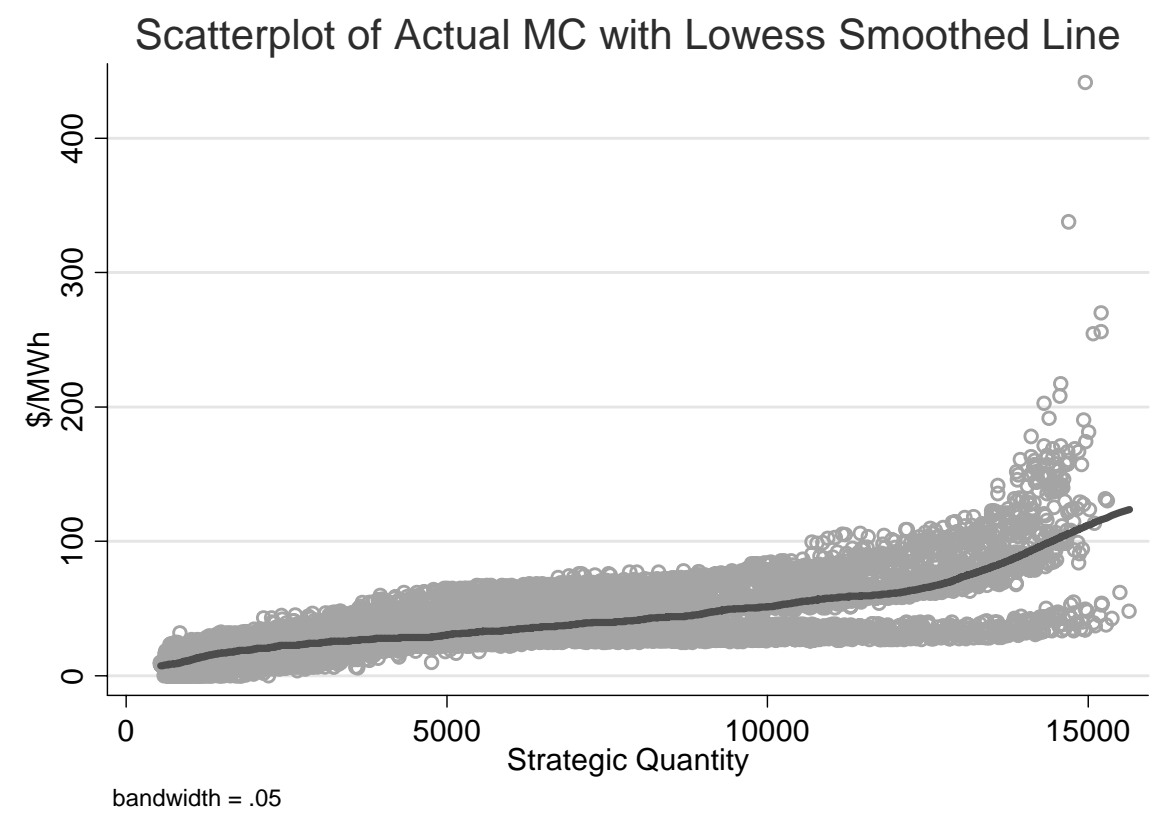

Figure 1: Scatterplot of Actual MC versus Strategic Quantity

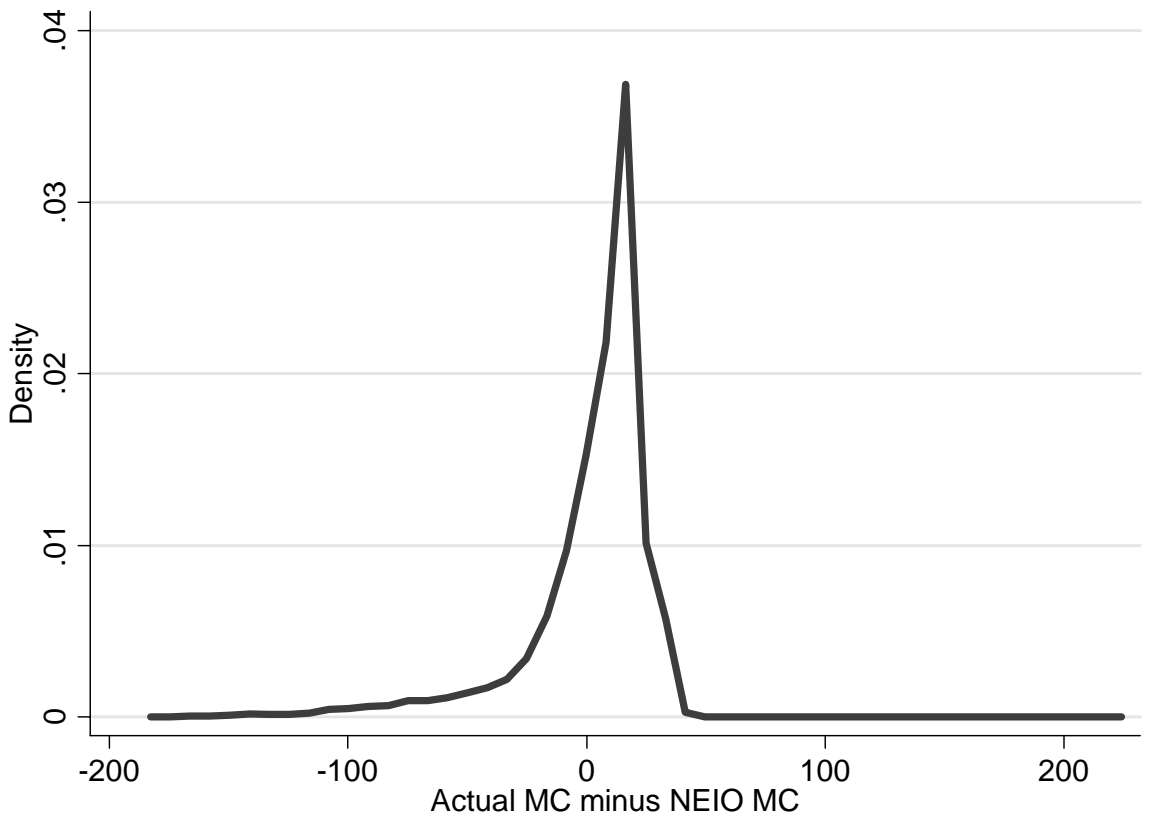

Figure 2: Kernel Density Estimate of Actual MC minus NEIO MC 


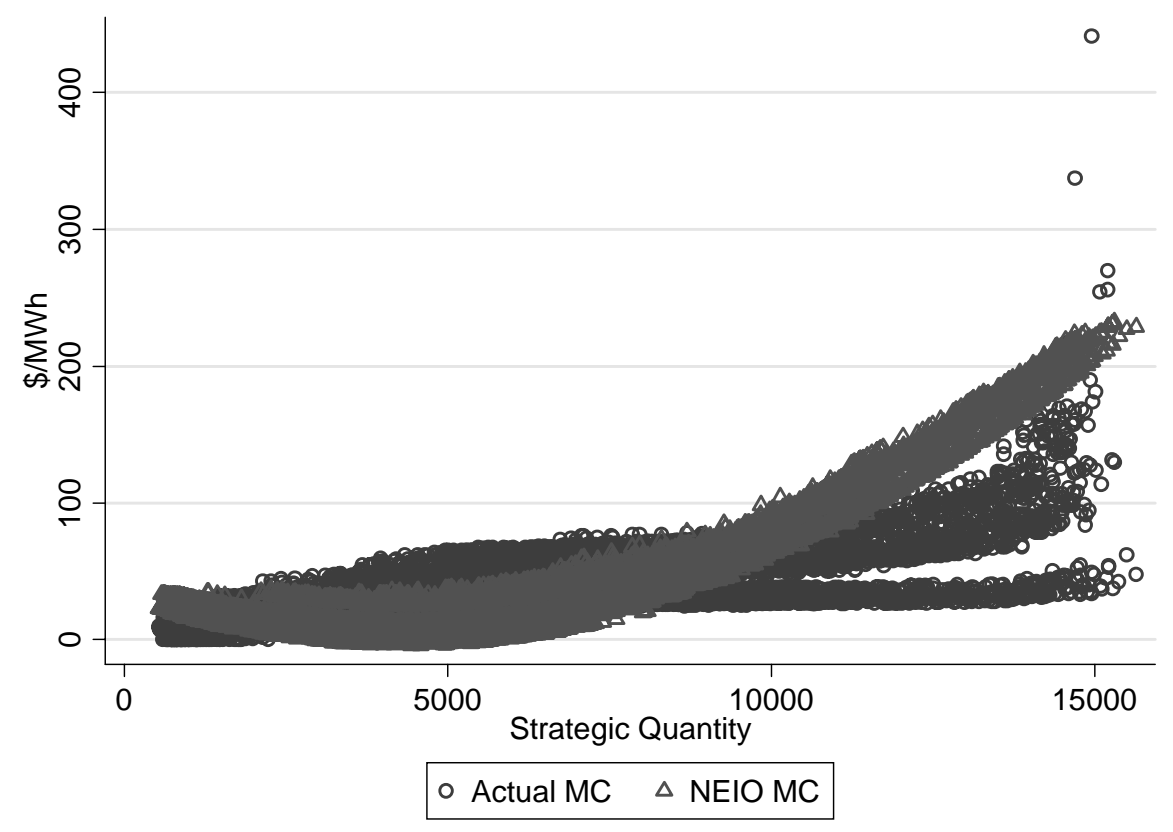

Figure 5: Scatterplot of Actual MC and NEIO MC Estimates versus Strategic Quantity

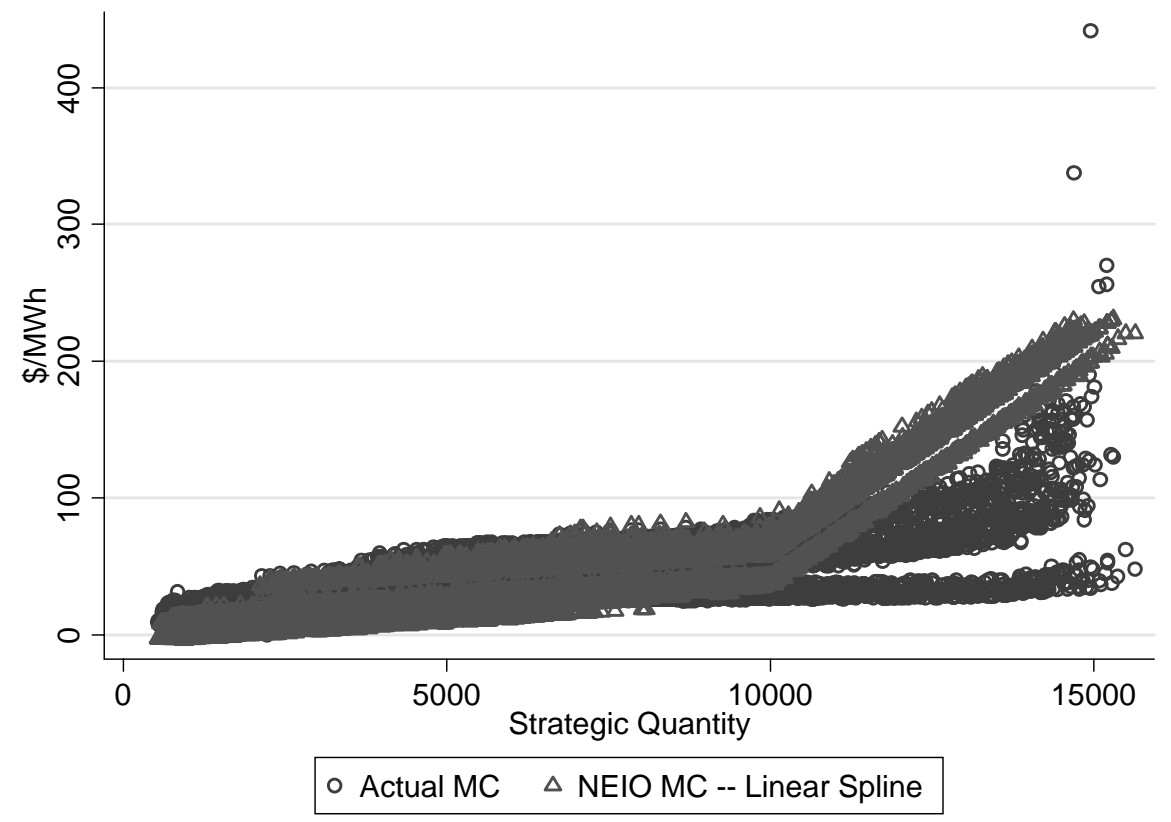

Figure 6: Scatterplot of Actual MC and Endeogenous Spline NEIO MC Estimates 